\title{
Word form retrieval in spoken word production
}

\section{Sunita Balbir Singh, BSc DipGrad}

\author{
School of Psychology \\ Faculty of Science \\ Victoria University of Wellington
}

April 2011

This dissertation is presented for the degree of

Master of Science in Cognitive and Behavioural Neuroscience 


\section{CONTENTS}

$\begin{array}{ll}\text { ABSTRACT } & 6\end{array}$

\section{CHAPTER ONE}

$\begin{array}{ll}\text { INTRODUCTION } & 9\end{array}$

Theories of Single Word Production 10

The two-stage interactive activation model $\quad 10$

The WEAVER model 13

$\begin{array}{ll}\text { The Auditory Picture-Word Interference Task } & 17\end{array}$

$\begin{array}{ll}\text { The Phonological Facilitation Effect } & 19\end{array}$

Begin and End Related Distractors $\quad 23$

$\begin{array}{ll}\text { The present study } & 25\end{array}$

\section{CHAPTER TWO}

PHASE ONE: The auditory picture-word interference task

on young controls

$\begin{array}{ll}\text { Introduction } & 29\end{array}$

$\begin{array}{ll}\text { Method } & 30\end{array}$

$\begin{array}{ll}\text { Participants } & 30\end{array}$

$\begin{array}{ll}\text { Materials } & 30\end{array}$

$\begin{array}{ll}\text { Design } & 32\end{array}$

$\begin{array}{ll}\text { Procedure } & 35\end{array}$

$\begin{array}{ll}\text { Data Analysis } & 37\end{array}$

$\begin{array}{ll}\text { Results } & 37\end{array}$

$\begin{array}{ll}\text { Discussion } & 44\end{array}$ 


\section{CHAPTER THREE}

PHASE TWO: The auditory picture-word interference task

on older controls and an aphasic individual, NP

Introduction $\quad 50$

$\begin{array}{ll}\text { Case study } & 55\end{array}$

$\begin{array}{ll}\text { Method } & 60\end{array}$

$\begin{array}{ll}\text { Participants } & 60\end{array}$

$\begin{array}{ll}\text { Materials } & 60\end{array}$

$\begin{array}{ll}\text { Design } & 60\end{array}$

$\begin{array}{ll}\text { Procedure } & 61\end{array}$

$\begin{array}{ll}\text { Data Analysis } & 61\end{array}$

$\begin{array}{ll}\text { Results } & 61\end{array}$

$\begin{array}{ll}\text { Discussion } & 69\end{array}$

\section{CHAPTER FOUR}

CONCLUSION

$\begin{array}{ll}\text { Purpose and findings of the study } & 74\end{array}$

$\begin{array}{ll}\text { Summary } & 76\end{array}$

$\begin{array}{ll}\text { Implications of current study and future directions } & 77\end{array}$

$\begin{array}{ll}\text { REFERENCES } & 79\end{array}$

$\begin{array}{ll}\text { APPENDICES } & 91\end{array}$ 


\section{LIST OF FIGURES AND TABLES}

\section{CHAPTER ONE}

Figure 1.1: The two-step interactive activation model

Figure 1.2: The WEAVER (Word Encoding Activation and VERification) model of word production

Figure 1.3: Layout of the auditory picture-word interference paradigm of the present study

Figure 1.4: A layout of the auditory picture-word interference task in the current study

Table 1.1: A summary of studies that look at the phonological facilitation effect across different SOAs

\section{CHAPTER TWO}

Figure 2.1: The difference in total incidence of error between the phonologically related conditions and their respective unrelated controls

Figure 2.2: The percentage difference in latency between each phonologically related condition and its respective unrelated controls across the four SOAs

Table 2.1: The distribution of blocks across groups over the two testing sessions Table 2.2: Tally report of the total number of outright errors and omissions made across the different distractor and SOA conditions

Table 2.3: Geometric mean naming latencies for correct responses across the four distractor conditions and SOAs 


\section{CHAPTER THREE}

Figure 3.1: The percentage difference in latency between each phonological condition and its respective unrelated control across the four SOAs for NP and the older controls

Table 3.1: NP's description of the 'Cookie Theft' picture from the Boston Diagnostic Aphasia Examination (taken from Wilshire et al., 2007)

Table 3.2: Performance of NP on standard language tests (taken from Wilshire et al., 2007)

Table 3.3: NP's responses on the Wilshire Length and Frequency Naming Test and its corresponding repetition test (taken from Wilshire et al., 2007)

Table 3.4.: A tally report of the total number of outright naming errors and omissions made across the different distractor and SOA conditions for the older controls and NP Table 3.5: Geometric mean naming latencies of correct responses across the four distractor conditions and SOAs for the older controls and NP

\section{APPENDICES}

APPENDIX C: A tally report of the types of outright naming errors and omissions made across the different distractor and SOA conditions for the young controls. APPENDIX D: A tally report of the types of outright naming errors and omissions made across the different distractor and SOA conditions for the older controls; APPENDIX D: A tally report of the types of outright naming errors and omissions made across the different distractor and SOA conditions for NP 


\begin{abstract}
In the auditory picture-word interference task, participants name pictures whilst ignoring auditory distractor words. Previous studies have reported faster naming latencies when distractors are phonologically related to the target (e.g., tigertypist) than when they are unrelated. By varying the position of overlap of the shared phonemes and the onset of the distractor, this task may provide valuable insights into the time course of phonological encoding. In the current study, participants named pictures while hearing distractor words that were: begin-related (e.g., letter-lesson); end-related (e.g., letter-otter); or unrelated to the target (e.g., letter-cabin). Distractor onsets varied from $-200 \mathrm{~ms}$ (before target) to $+400 \mathrm{~ms}$ (after target). The study was carried out in two phases: in the first phase, the task was administered to a group of 24 young control participants; in the second phase, it was administered to an individual with aphasia, NP, and a group of six older controls. Phonological facilitation effects of begin-related distractors displayed a fairly consistent pattern across the four distractor onsets for all participant groups. In almost all instances, these effects were significant but were noticeably stronger at early onsets especially around the onset of the target presentation, consistent with previous findings in the literature. Only NP showed strong begin-related facilitation effects at the latest onset. The end-related distractors however, produced somewhat different facilitation effects across the different groups. For the young controls and NP, these effects were stronger and significant at later onsets. The older controls only displayed marginally significant effects at $200 \mathrm{~ms}$ after the target. Findings from the current study provide support for serial pattern of phoneme retrieval in multisyllabic words, in which a word's first syllable becomes available before later syllable(s).
\end{abstract}




\section{DECLARATION}

I certify that the research described in this dissertation has not already been submitted for another degree.

I certify that to the best of my knowledge, all sources used and any help received in the preparation of this dissertation has been acknowledged.

I certify that approval for the research described in this dissertation has been granted from the ethics review committee of:

School of Psychology Human Ethics Committee (SOPHEC), Victoria University of Wellington (Protocol Number: R/M 16615: $27^{\text {th }}$ May 2009)

Sunita Balbir Singh 


\section{ACKNOWLEDGEMENTS}

I would like to thank my supervisor, Dr Carolyn Wilshire, for all her help in the planning and development of this research project. I would also like to thank her for her help, feedback, patience and most importantly support and encouragement through the good times and the bad times.

I would also like to acknowledge Catherine Hodgson for her contribution to the stimuli used in this study. Also thanks to Paula Speer for her assistance in setting up the pre-testing task; Bridget Burmester for her contribution to data collection, Matthew Warren and Corinne Bareham

Finally and most importantly, thanks to all participants, especially NP for their time and patience during testing. 


\section{CHAPTER ONE}

\section{INTRODUCTION}

The process of producing a word is an important function of language that enables us to express thoughts as well as exchange knowledge and ideas with one another. However, the ability to communicate a single word is far more complex than what it appears on the surface. Researchers have been constantly interested in developing theoretical frameworks to breakdown and identify processes involved in word production. It is important to identify these processes, as findings could be used to help understand individuals with language disorders such as aphasia, and to develop treatment tools for rehabilitation (word production studies on aphasic individuals can also be used in return to understand normal function). The major processes involved in word production can be broken down into two main steps. First, the desired concept which contains the semantic and syntactic properties of the word the speaker wishes to say is retrieved. Second, the linguistic representations information such as phonetic structure and sound information of the word is encoded (Garrett, 1975). The current study is interested in this second stage of word production because a crucial component of word finding is the ability to retrieve the sound information. This process can go wrong in cases of language impairments like aphasia where an aphasic person struggles to find sound information of a word to be articulated. This in turn leads to an inability of a person with aphasia to express themselves causing a lot of frustration for the speaker and listener.

There have been numerous theories on word production processes (see Garrett, 1975; Shattuck-Hufnagel \& Klatt, 1979; Stemberger, 1985; Levelt, 1990; Dell \& O’Seaghdha, 1991,1992; Dell, Schwartz, Martin, Saffran, \& Gagnon, 1997; Roelofs, 1997; Levelt Roelofs \& Meyer, 1999). This review will focus on the two 
main theoretical models that have most heavily influenced modern studies on single word production, the two-step interactive activation model (Dell \& O'Seaghdha, 1991,1992; Dell et al., 1997; Foygel \& Dell, 2000) and the WEAVER model (Roelofs, 1997). These two models were selected because they are most detailed in aspects of phonological encoding. Each model will be explained with examples drawn from findings in recent literature. Behavioural findings of single word production through the auditory picture-word interference paradigm and related phenomena (e.g. phonological facilitation, semantic interference) as well as recent neuroimaging studies will also be reviewed. The aims and hypotheses of the current study will then be introduced.

\section{Theories of Single Word Production}

\section{The two-step interactive activation model}

One of the most influential frameworks of speech production is the two-step interactive activation model (Dell \& O’Seaghdha 1991; Dell et al, 1997; Foygel \& Dell, 2000). It is one of the very few models that have been computer implemented (Dell, 1986; see also Harley, 1993; Schade \& Berg, 1992). The model is based on a simple localist network spread across three levels that are interconnected by individual nodes. These nodes represent the different types of linguistic units which include semantic features, lexical items and phonemes (Foygel \& Dell, 2000). Connections are based on shared semantic and phonological features. Figure 1.1 gives a clear illustration of the layout of this model. 


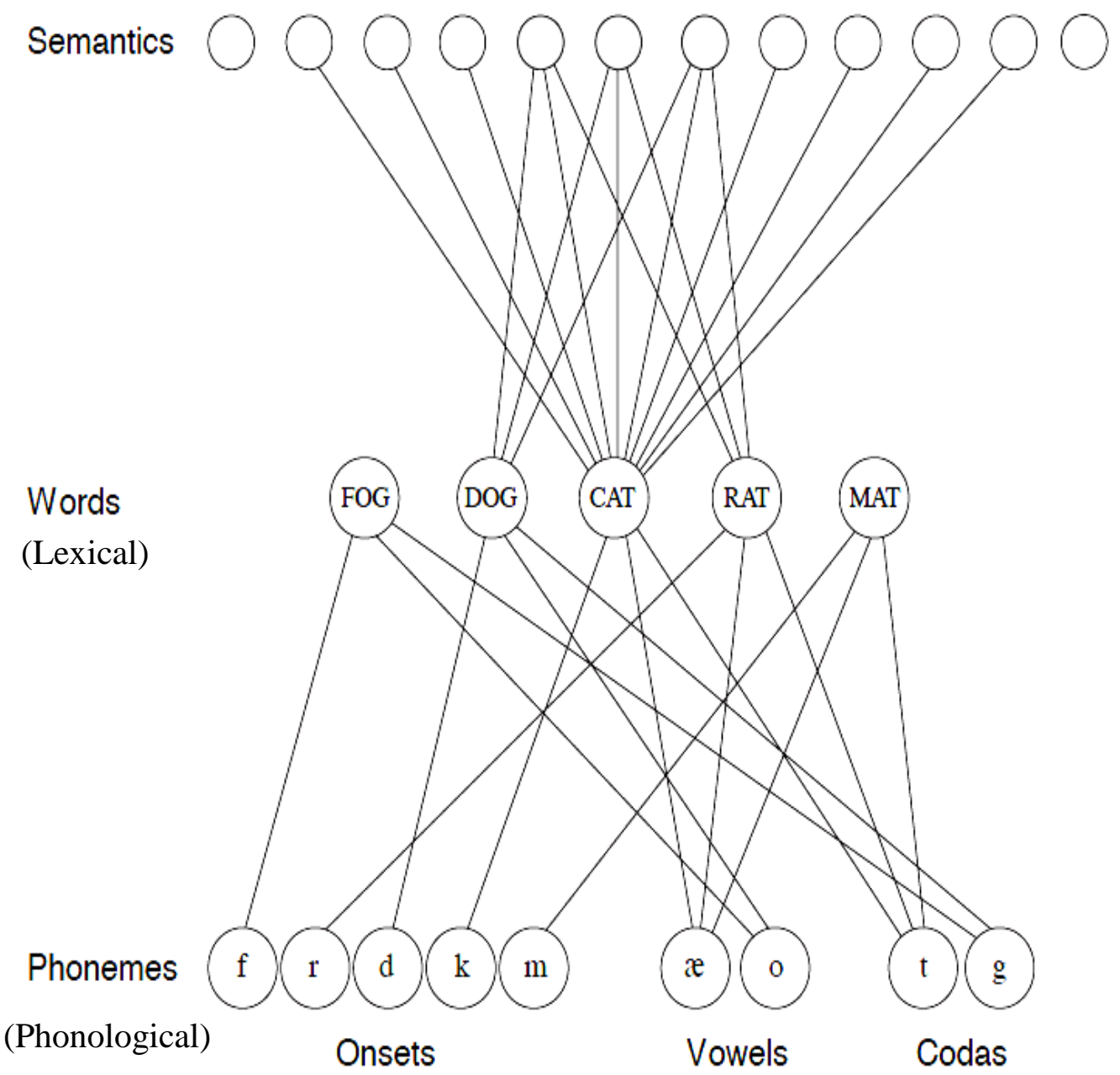

Figure 1.1. Dell et al.'s two-step interactive lexical network (from Levelt, 1999).

Each node in the upper level represents semantic features; the middle nodes represents lemmas or words and the bottom level represents phonemes (these include onsets, nuclei and codas). Activation automatically spreads proportionally to immediately connecting nodes in the following level. This network also allows for activation to feed back from phonological nodes to corresponding lexical nodes and then to semantic nodes.

This model proposes two major stages in converting a concept into a string of phonemes for production. During the first stage, the lexical concept that shares the most semantic features to the target concept is selected. Here, units in the semantic 
level automatically spread activation proportionally to immediately connected nodes in the lexical level. This means that all lexical nodes associated to the target will receive some activation (Foygel \& Dell, 2000). Referring to the example outlined in Figure 1.1; if the target item is 'cat', then the lexical nodes for 'dog' and 'rat' will also become activated as these items share similar features. The lexical node for 'cat' shares the greatest number of semantic features with the target and is therefore selected for production by receiving an additional boost to its activation levels. The second stage involves another automatic spread of activation from this highly activated lexical node to its corresponding phonological nodes, which contain the phonemes of the target concept. So, for the lexical node 'cat', activation spreads to the phonological nodes $/ \mathrm{k} /$, /æ/ and $/ \mathrm{t} /$. As activation spreads automatically in a cascading fashion, this means that any node once activated, is capable of transmitting activation to other nodes to which it is directly connected. This means that phonological units can become substantially activated even before lexical selection is complete (Stemberger, 1985; Dell, 1986; Dell et al., 1997). Word production models that adopt the concept of spreading activation like this one tend to suggest that phonemes are activated in a serial fashion. This is where initial phonemes receive higher activation than the following phonemes of the word to be articulated (Hartley \& Houghton, 1996; Sevald \& Dell, 1994; Vousden, Brown \& Harley, 2000; Meyer \& Belke, 2007). Consequently, the processes of lexical selection and phonological encoding are not two completely separate entities. Instead these processes overlap with activation continuously flowing from one processing level to the other (Jescheniak \& Schriefers, 2001). A unique feature to this model is its bi-directional connections, allowing activation to spread not only forwards from semantic and lexical representation(s) to phonological representations, but also backwards from 
phonological to lexical representation(s). The lexical representation(s) can then feed back to semantic representations (Dell et al., 1997).

\section{The WEAVER model}

The WEAVER (Word-form Encoding Activation and VERification) model by Roelofs (1997) is a comprehensive model of word production, which focuses in particular on word-form encoding. It follows the two-step concept, however each level is broken down into smaller steps. Similar to the two-step interactive activation model, when an item is to be named, the target concept is first activated. Other semantically related concepts are also activated. These activated concepts then spread activation down to their corresponding lemmas (word representations). Like all models in this network-style framework, there is competition between the activated lemma units, and the most highly activated lemma is selected for production. Once this selection has been made, activation then spreads down to the form level where the phonological code of the corresponding lemma is retrieved. Retrieval of the phonological code is divided into a number of sub stages. The retrieval process in the WEAVER model is outlined in Figure 1.2. 


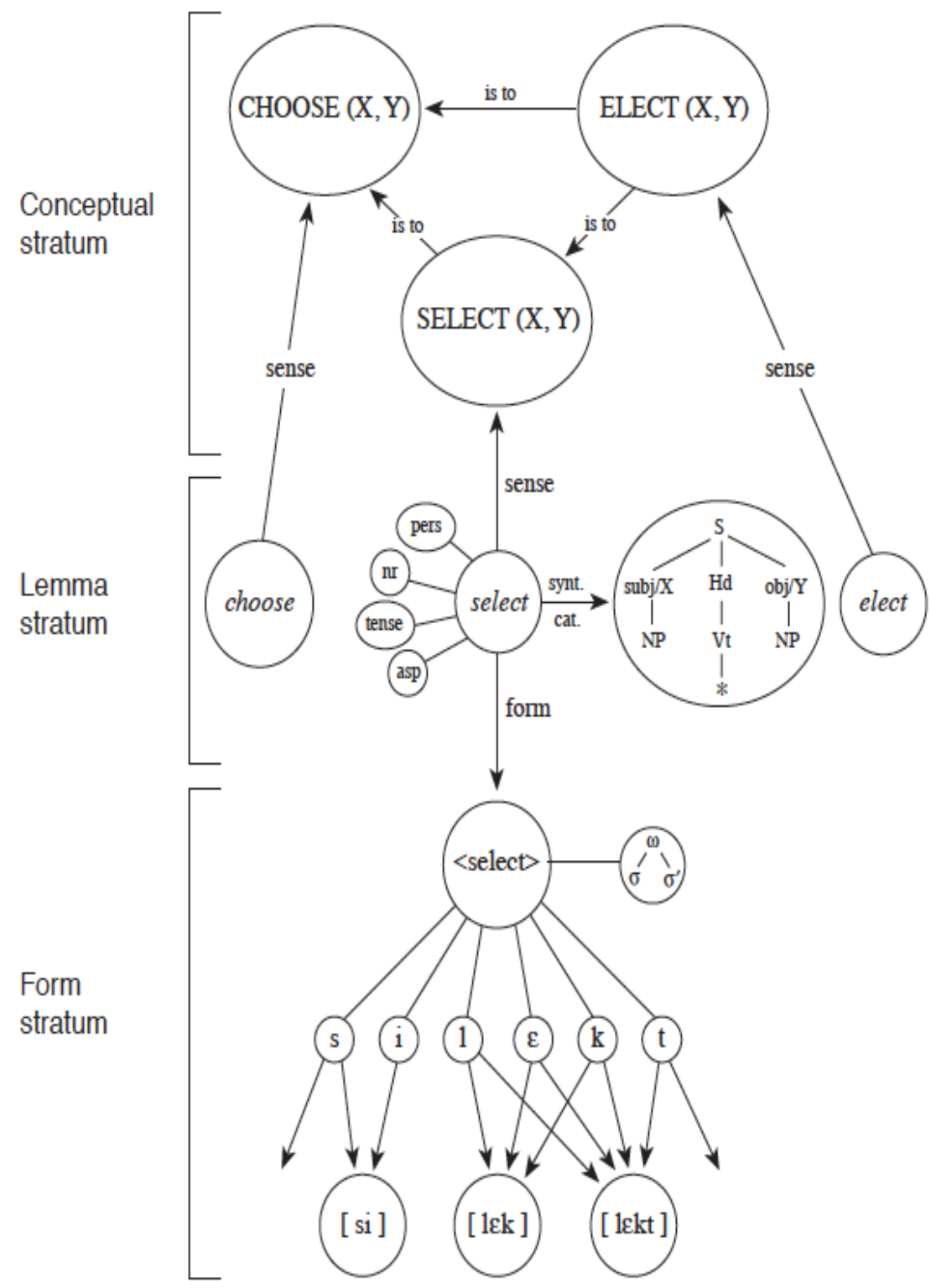

Figure 1.2. The WEAVER model (from Levelt, 1999). Here, the target word 'select' becomes activated at the conceptual stratum or level. Semantically related words such as 'choose' and 'elect' are also activated. All of these activated concept nodes spread activation to their corresponding lemmas. Through the checking mechanism (even though all similar concepts are activated) the target lemma 'select' is chosen and only its lemma node can then send activation down to the form stratum for phonological encoding. 
In this example, the morpheme node <select> first receives activation from its corresponding lemma 'select'. Activation then spreads forward to directly linked phonological segments where metrical structure is also chosen. Here, phonemes are retrieved in a strictly parallel fashion where all phonemes of the target lemma are activated at the same time. It is important to note that within this model later phonological processes are performed in a sequential manner and not in parallel (Roelofs, 1997; Levelt et al., 1999, Roelofs, 2004; Meyer \& Belke, 2007). After all phonemes of the target have been retrieved, the process of syllabification is initiated. This is where the segments $(/ \mathrm{s} /, / \mathrm{i} /, / \mathrm{l} /, / \varepsilon /, / \mathrm{k} /, / \mathrm{t} /)$ and metrical structure are organised into syllables ([si] and [lekt]). The process is unidirectional, where the initial segment is computed first, followed by the second then third and so on (Roelofs, 1997; Levelt et al., 1999, Roelofs, 2004). Within this model, the syllabic position of a word's phonemes is not stored, but rather computed online after the word's sound form representation has been retrieved. Once the resultant phoneme sequence has been syllabified, the motor commands associated with each syllable are retrieved from the mental syllabary -a library of overused high-frequency syllables an individual may use (Roelofs, 1997).

Unlike interactive models of word production, there is no cascade spread of activation here. Instead, at each phase, a single unit is first selected before processing of the subsequent stage begins. Also, in this model, activated nodes are verified to see whether they are supposed to be integrated into the final product (similar to a quality control checking mechanism) before processing of the subsequent stage begins (Roelofs, 1997; Levelt et al., 1999, Levelt, 1999). In this way, the WEAVER model controls the spread of activation, so only the winning lemma can activate its respective phonological representation. This means that no two phonological concepts 
are activated at the same time except in very special cases (for example, where two synonyms exists for the same word). Furthermore, within this model, activation cannot flow back from the word form level to the corresponding lemma representation.

These two models essentially attempt to provide an in depth explanation of the processes involved in single word production. The WEAVER model, like other models derived from the same class (see Garrett, 1975; Levelt et al., 1991; Levelt et al., 1999), follows a strict feedforward pattern where only the lemma selected at the lemma level is allowed to be phonologically encoded. In contrast, within the interactive model, processing at one level begins as soon as information is available from the previous connected level. In addition, information processed in the lower levels can influence processing at the upper levels. Some evidence favours the interactive or cascading class of models (see Cutting \& Ferreira, 1999; Morsella \& Miozzo, 2002; Navarrete \& Costa, 2005; for examples). Strict feedforward activation models, however, need certain modifications and additional rules to account for some of these effects (Roelofs, 1997; Levelt et al., 1999). We will return to this issue of strict feedforward activation later after the auditory picture-word interference task has been introduced.

In addition, these models also differ in the manner in which phonemes are ordered during the phonological encoding process (from now on, this will be referred to as the phoneme ordering process). Early models like Dell's (1986) model suggested that all phonemes of a syllable are activated and selected in parallel. The WEAVER model suggests that phonemes are activated and retrieved at the same time or in parallel. However, the syllabification process that soon follows is done in a serial fashion from the onset to the end of the word. The two-step interactive 
activation model suggests that phonemes are activated at the same time but retrieved in a serial fashion (Dell et al., 1997; Foygel \& Dell, 2000).

Previous studies investigating the phoneme ordering process have traditionally relied on error analysis like slips of the tongue (Shattuck-Hufnagel, Keller \& Gopnik, 1987). Therefore, paradigms like the picture-word interference task were introduced so that phoneme positioning could be manipulated to observe effects on picture naming.

\section{The Auditory Picture-Word Interference Task}

The auditory picture-word interference task has been used extensively by researchers to study word production (e.g. Schriefers, Meyer \& Levelt, 1990; Meyer \& Schriefers, 1991; Starreveld, 2000; Wilshire, Keall, Stuart \& O’Donnell, 2007; Ventura, Kolinsky, Querido, Fernandes \& Morais, 2007). In this task, participants must name a picture while ignoring an auditory distractor word (e.g., Damian \& Martin, 1999; Jescheniak \& Schriefers, 1998; Schriefers et al., 1990; Wilshire et al., 2007). This task may be able to provide us with valuable information on processes involved in word production by teasing apart the various stages. This can be achieved by observing whether the type of distractors used produce faster naming latencies (facilitation) or slower naming latencies (interference) during the task. If faster naming latencies are observed, then the distractor must be involved in activating lexical and/or phonological representations required to produce the target's name (Meyer \& Schriefers, 1991; Wilshire \& Saffran, 2005; Wilshire et al., 2007)

This task may also be helpful in providing insights about the time course of word production by varying the time between the onset of the auditory distractors and the picture presentation. This is called the stimulus onset asynchrony (SOA) 
(Starreveld, 2000; Jescheniak \& Schriefers, 2001; Wilshire et al., 2007). Depending on the SOA of the distractor, varied naming latencies may be observed which could be isolated to a certain stage of word processing.

The nature of distractor stimuli has shown to exert varied effects on this task. That is, performance on the task depends on whether the auditory distractor is semantically or phonologically related to the target. Semantically related distractors have been shown to produce an interference effect by slowing down naming latencies when presented at least $200 \mathrm{~ms}$ before presentation of the picture target (Schriefers et al., 1990; Damian (in press)). Some researchers have argued that the semantic interference effect reflects processes occurring during lexical selection (Bloem, van den Boogaard \& La Heij, 2004). The rationale behind this suggestion is that presenting a semantically related distractor around the time of target presentation results in activation of the distractor's and the target's lexical representations. The distractor's lexical representations are sufficiently active to compete with the target's lexical representations therefore slowing down the naming process. Others have argued that semantic interference effects occur at earlier processing stages; at the prelexical or conceptual stage. When a semantic distractor is placed at an early onset, the result is strong competition between selection of the target and distractor's semantic representation that is to be lexicalized (Costa, Alario \& Caramazza, 2005; Kuipers, La Heij \& Costa, 2006).

Phonologically related distractors on the other hand, have been shown to produce a facilitation effect by reducing naming latencies (relative to unrelated distractors) when presented at the time of target presentation ( $0 \mathrm{~ms}$ onset) or up to $200 \mathrm{~ms}$ after picture presentation (Schriefers et al., 1990; Meyer \& Schriefers, 1991; Meyer \& Van Der Meulen, 2000; Damian (in press)). This phenomenon is known as 
the phonological facilitation effect. Researchers have proposed various explanations for this phonological facilitation effect, which will be discussed in further detail later. These findings of the differences between semantic interference and phonological facilitation highlight the issue of interactivity previously discussed. Some researchers have inferred semantic interference effects occurring solely at pre-lexical stages and phonological effects occurring at central and post-lexical stages of the word production model (Schriefers et al., 1990; Ayora et al., (in press)). Contrary to this observation, others have argued that semantic interference and phonological facilitation are not discrete effects but instead they overlap (Martin, Gagnon, Schwartz, Dell \& Saffran, 1996; Starreveld, 2000). These observations of semantically and phonologically related distractors suggest that the nature of the distractor used may exert an influence on different levels of the picture naming processes, thus providing us with information on the time course of word production (Schriefers et al., 1990; Meyer \& Schriefers, 1991).

\section{The Phonological Facilitation Effect}

According to the WEAVER model, during the auditory picture word interference task, if a distractor word does not share phonological segments with the target word, this will result in competition between the activated segments, hence slowing down naming latencies relative to a no-distractor condition. However, if the distractor shares phonemes with the target, this competitive effect will be substantially reversed for two reasons. First, if the phonologically related distractor is presented early enough, then the participant may use this distractor as a cue to aid in preparation of the motor commands for reproduction of the upcoming word (Guenther, Hampson \& Johnson, 1998; Kent, Adams \& Turner, 1996). Second, the 
activated phonemes of the distractor word may also facilitate word form encoding of the target word, enabling phonemes that are shared between target and distractor to become sufficiently activated sooner (Roelofs, 1997; Meyer, 1996; Meyer \& Schriefers, 1991). In this model, phonologically related distractors cannot exert an influence on lemma selection, because: (i) there is no feedback, so that activation at the word form encoding level cannot influence processes occurring at the higher, conceptual/lemma level; and (ii) only one word can activate its phonemes at a time (Meyer et al., 1998; Meyer \& Schriefers, 1991).

There is some variability across studies, with some studies reporting significant phonological facilitation effects when the distractor is presented from $150 \mathrm{msec}$ before the onset of the picture to be named, until $200 \mathrm{~ms}$ after its onset (see e.g., Damian \& Martin, 1999; Meyer \& Schriefers, 1991, Schriefers et al., 1990; Damian (in press) but see Jescheniak \& Schriefers, 1998 who failed to find an effect). Some have also reported effects as early as $300 \mathrm{~ms}$ prior to the target picture (e.g., Jescheniak \& Schriefers, 2001; see also Starreveld, 2000). Table 1.1 lists some previous studies that adopted phonological distractors. A brief glance of this table suggests that the distractor onset of $0 \mathrm{~ms}$ (time of target presentation) tends to exhibit facilitation effects most commonly over other onsets, closely followed by $150 \mathrm{~ms}$ (after target presentation) and $150 \mathrm{~ms}$ (before target presentation). 
Table 1.1.

Previous studies looking at phonological facilitation effects across specific SOAs.

Phonological distractors are begin-related to the target and are all bisyllabic (an adaptation from Abel et al, 2009).

\begin{tabular}{|c|c|c|c|c|c|c|c|c|}
\hline \multirow{2}{*}{$\begin{array}{c}\text { Auditory } \\
\text { Distractor } \\
\text { Type }\end{array}$} & \multirow{2}{*}{$\begin{array}{l}\text { Selected } \\
\text { Studies }\end{array}$} & \multicolumn{7}{|c|}{$\mathrm{SOA}(\mathrm{ms})$} \\
\hline & & -300 & -150 & -100 & 0 & 100 & 150 & 200 \\
\hline Phonological & Schriefers et al 1990 & & & & $\mathrm{X}$ & & $\mathrm{X}$ & \\
\hline Phonological & Meyer \& Schriefers 1991 & & $\mathrm{X}$ & & $X$ & & $\mathrm{X}$ & \\
\hline Phonological & Damian \& Martin 1999 & & & $\mathrm{X}$ & $\mathrm{X}$ & $\mathrm{X}$ & & $\mathrm{X}$ \\
\hline Phonological & Starreveld 2000 & $\mathrm{X}$ & $\mathrm{X}$ & & $\mathrm{X}$ & & & \\
\hline Phonological & $\begin{array}{l}\text { Jescheniak \& Schriefers } \\
2001\end{array}$ & $\mathrm{X}$ & $\mathrm{X}$ & & & & $\mathrm{X}$ & \\
\hline Phonological & Wilshire et al 2007 & & & & $\mathrm{X}$ & & & \\
\hline Phonological & Damian (in press) & & & & $\mathrm{X}$ & & & $X$ \\
\hline
\end{tabular}

Initial findings on the auditory picture-word interference task suggested that the phonological facilitation effect was occurring at the phonological encoding stage of word production. It was postulated that shared phonological segments between the target and phonological distractor overlapped, therefore reducing the time needed to activate the target's whole phonological representation (Schriefers et al., 1990; Meyer \& Schriefers, 1991). However, recent findings on this effect (e.g. Damian \& Martin, 1999; see also Ventura et al., 2007; Wilshire et al., 2007) suggest that shared phonological units between the phonological distractors and target activate the target's lexical representation through feedback activation. This feedback process occurs from the phonological level to the lexical level which can only be explained by 
the two-step interactive activation model (Dell, 1986; 1988; Dell \& O'Seaghdha, 1992).

Starreveld (2000) discovered phonological facilitation effects at early distractor onsets, most notably at $300 \mathrm{~ms}$ before target presentation. He suggested that these phonological effects were due to some form of implicit or explicit learning where participants developed a strategy for target naming. This learning may have occurred when participants were presented with a phonologically related distractor at a later SOA, thus the participants might have established that these distractors were somewhat helpful in facilitating the naming process.

There is some converging evidence from neuroimaging studies to support the idea that phonologically related distractors may facilitate lexical selection as well as phonological encoding. Abel et al (2009) used functional magnetic resonance imaging (fMRI) to isolate the neural regions implicated in the phonological facilitation effect. Using a task in which auditory distractors were presented $200 \mathrm{~ms}$ prior to the target picture, they observed a marginally significant signal reduction in the left supramarginal gyrus (SMG / Brodmann area 40) when the distractors were phonologically related to the target. This region has previously been associated with phonological level processes, particular phonological encoding for production (Benson, Shremata, Bouchard, Segarra, Price \& Geschwind, 1973; Caplan, Vanier \& Baker, 1986; Damasio \& Damasio, 1998). There was also enhanced activation in the left mid to posterior superior temporal gyrus, a region that has previously been associated with acoustic and phonological processing (Hickok and Poeppel, 2005; Wise et al., 2001). Using a task in which auditory distractors were presented simultaneously with the target picture (i.e., 0 ms), De Zubicaray and McMahon (2009) found reduced signal activation in the left middle and superior temporal gyrus 
when the distractor was phonologically related to the target. These regions, particularly the middle temporal gyrus, have previously been associated with lexical retrieval (Gracco, Tremblay \& Pike, 2005; De Zubicaray et al., 2006). Therefore, the effect of phonological distractors is not just restricted to the phonological encoding stage of word production but also exerts an influence over the lexical selection stage. These findings provide evidence towards an interactive model of word production.

\section{Begin- and End-related distractors}

Most studies have mainly focused on the effects of begin-related distractors. However, it is necessary to consider that the position of shared phonemes between the target and distractor words may also be important. Begin-related distractors used in several prior studies have consistently produced a facilitatory effect on target naming compared to an unrelated distractor (Schriefers et al., 1990; Meyer \& Schriefers, 1991; see also Damian \& Martin, 1999; Starreveld, 2000; Jescheniak \& Schriefers, 2001; Taylor \& Burke, 2002; Starreveld \& La Heij, 2004; Wilshire et al., 2007). As mentioned previously, presentation of a begin-related distractor activates shared features with the target therefore producing faster latencies compared to an unrelated condition (Meyer \& Schriefers, 1991). Presenting a begin-related distractor at later onsets may interfere with the lexical selection stage resulting in competition between the target and distractor's lexical representations (Damian \& Martin, 1999; Taylor \& Burke, 2002; Wilshire et al., 2007). In addition, it was suggested that the target tends to be favoured for production over the distractor, as the distractor's lexical representation does not receive additional activation from the semantic level and is never produced (Wilshire et al., 2007). Some studies have found facilitatory effects at very early distractor onsets such as $300 \mathrm{~ms}$ before the target is presented (e.g. 
Starreveld, 2000; Jescheniak \& Schriefers, 2001). These early phonological facilitation effects still remain unclear. Meyer and Schriefers (1991) postulated that at very early distractor onsets, activation of shared phonological segments between target and distractor might have already decayed when phonological encoding of the target is initiated.

The two word production models reviewed make different predictions on how begin related and end related distractor conditions may affect the phonological encoding process. Within the two-step interactive model (Dell et al., 1997; Foygel \& Dell, 2000), phonemes of a word are activated in a parallel or simultaneous pattern but are retrieved in a sequential manner. Therefore begin-related and end-related distractors would produce different patterns of facilitation (Meyer \& Schriefers, 1991; Wilshire \& Saffran, 2005). Begin-related distractors would have a better chance of activating the target's lexical representation through early feedback activation. However, end-related distractor would only have a limited time to exert their effects due to late activation, so these facilitation effects would mainly occur at the phonological level (Wilshire \& Saffran, 2005; see also Sevald \& Dell, 1994). Meyer and Schriefers (1991) predicted from the WEAVER model that beginrelated and end-related distractors would behave in the same manner by reducing naming latencies. This means that there should be no difference in facilitation between begin-related and end-related distractors, due to similar time course effects. However, they observed that end-related distractors produced facilitatory effects when presented at later onsets (i.e. $0 \mathrm{~ms}$ or target presentation) compared to beginrelated distractors. They suggested that the reason for this finding could be that phonological encoding of the end phonemes of the target word occurs later compared to the initial phonemes. In addition, they also suggested that encoding within a 
syllable is done in a serial pattern (see also Jescheniak \& Schriefers, 1998; Roelofs, 2004). The only concern here is that these suggestions assume that distractors exert their effects at the phonological stage of the WEAVER model. If distractors do exert their effects at the phonological stage of word production, we should expect to see late phonological facilitation effects for begin-related distractors (Meyer \& Schriefers, 1991; Wilshire et al., 2007). Also, these effects cannot be attributed to post-retrieval processes (e.g., syllabification), because the auditory distractors are heard but never produced (Wilshire et al., 2007). Previous findings outlined in Table 1.1 show phonological facilitation effects occurring predominantly around the time of target presentation which suggests the involvement of higher levels of word production processes (i.e. lexical access). Therefore, it would be interesting to compare the differences between begin and end-related distractors on a picturenaming task. This may help us establish a clearer picture on the manner in which phonemes are retrieved (parallel or sequential) amongst normal individuals as well as provide evidence towards an appropriate model of phonological encoding. This in turn may help identify which component(s) of word production models are disrupted in aphasic individuals.

\section{The present study}

The current study is interested in understanding how phonemes of words are ordered during the retrieval process. We adopted the auditory picture-word interference paradigm (Schriefers et al., 1990; Damian \& Martin, 1999; Meyer \& Schriefers, 1991; Jescheniak \& Schriefers, 1998; Wilshire et al., 2007) where participants named a series of target pictures as quickly and as accurately as possible whilst ignoring auditory distractors. We manipulated the position of the phonemes shared between the target and distractor as well as distractor onset time to look at the 
order in which phonemes are retrieved during phonological encoding. By including both begin-related (e.g. ferry - feather) and end-related distractors (e.g. brother feather) as well as varying their onset, we may develop insight on how the time course and degree of facilitation varies depending on the position of the shared phonemes. Bisyllabic words were used for both targets and distractors in this study, so conditions were set up to work with syllables as opposed to phonemes (see Appendix A for a full list of stimuli used). Previous studies on this topic have relied mostly on monosyllabic targets and distractors (e.g. Schriefers et al., 1990; Meyer \& Schriefers, 1991; Damian \& Bowers, 2009; Ayora et al., (in press)) and many did not look at the effect of end-related distractors (e.g. Starreveld, 2000; Ventura et al., 2007; Wilshire et al., 2007; Damian, (in press)). The problem with using only monosyllabic words is that these make up approximately $12 \%$ of the English language and are therefore not a true representation of the language (Cutler, 1990 as cited in Carreiras \& Perea, 2002). Timing is compressed in a task using monosyllabic words so any distractor effects may be difficult to observe. Also, we planned to investigate an aphasic individual where phonological encoding of longer words are much more complex, so using bisyllabic targets and distractors may be able to produce marked distractor effects compared to monosyllabic ones.

The four auditory phonological distractor conditions were begin-related in which the first syllable is shared between the target and distractor (e.g. ferry feather); end-related in which the second syllable is shared between the target and distractor (e.g. brother - feather); and a corresponding unrelated control was assigned to each of the above two conditions. For the purposes of this study, they are referred to as the begin-unrelated and end-unrelated conditions (e.g. donkey - strumpet). Similarly to Wilshire et al. (2007), the onset of the auditory primes varied according 
to the presentation of the visual picture at four different onsets or SOAs $(-200 \mathrm{~ms}$, 0ms, 200ms and 400ms). See Figure 1.3 for an illustration of the set up.

Auditory distractors placed at these SOAs (Wilshire et al., 2007; Damian, (in press))

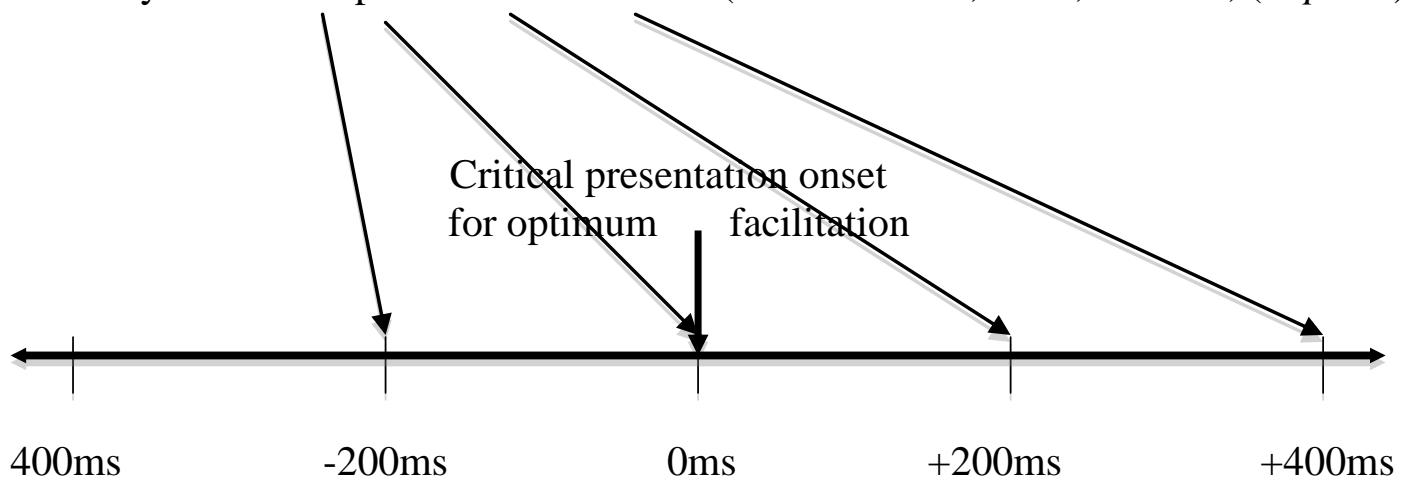

(Target picture presented at $0 \mathrm{~ms}$ )

Stimulus Onset Asynchrony (SOA)

Figure 1.3. Layout presentation of the auditory picture-word interference paradigm with phonological distractors placed at different positions in relation to the target picture (SOA). The critical timing of distractor onset for 'optimum facilitation' is marked according to general consensus from previous studies marked out in Table 1.1

The rationale for using an unusual range of SOAs compared to previous studies (e.g. Schriefers et al., 1990; Meyer \& Schriefers, 1991) followed the assumption that word production in aphasic speakers is abnormally slower compared to normal functioning individuals (Wilshire et al., 2007). In the second phase of this study, we planned to study the time course of word production and the phoneme ordering process in an aphasic individual using the auditory picture-word interference task. Hence, the rationale was adapted to the current study for consistency. A shorter timeframe between the distractor and target may not be able to capture any clear effects. Furthermore, slow word production processes in an aphasic speaker may require later presentations of distractors to exert influences over the appropriate word 
processing stages (Wilshire et al., 2007). As previously discussed, with regard to the issue of interactivity, semantic interference effects were observed at early SOAs, whereas phonological facilitation effects were observed at later SOAs (e.g. Levelt et al., 1999; Taylor \& Burke, 2002; Wilshire et al., 2007). The current study is interested only in phonological facilitation effects. So, gauging from the evidence presented so far, it would appear relevant to place our distractor onsets closer to the presentation of the picture target instead of placing them too early (i.e. $400 \mathrm{~ms}$ before target presentation).

The current study addresses these issues as well as expands the task to a group of older controls and an aphasic individual. This study was carried out in two parts and both utilised the same picture-word interference task. Naming latency was the main dependent variable and accuracy was also analysed. Stimuli and experimental design were also kept consistent. The first part involved 24 young non braindamaged controls; all were undergraduate psychology students at Victoria University of Wellington. The second part involved 6 older non brain-damaged controls and an aphasic individual, NP. NP's performance was compared to the group of older participants.

There are two possible expectations from this study. First, if results from the first phase of the current study show significant facilitation effects for begin-related distractors at earlier onsets and significant facilitatory effects of end-related distractors at later onsets; then the serial view of phoneme retrieval is supported. This is where the encoding of the first syllable occurs first followed by the second. Second, if there is no difference in facilitatory effects of begin- and end-related distractors on naming latencies across the different SOAs, then the parallel view of phoneme retrieval will be supported. 


\section{CHAPTER TWO}

PHASE ONE: The auditory picture-word interference task with young controls

\section{Introduction}

This phase of the study plans to investigate the phoneme ordering process using the auditory picture-word interference task on a group of young individuals. As mentioned previously, there is much debate as to whether phonemes are retrieved in a parallel or serial manner. The two-step interactive-activation model of Dell and colleagues (e.g., Dell, 1986; Dell \& O’Seaghdha, 1991; Dell et al., 1997; Foygel \& Dell, 2000) propose that within a syllable, phonemes are retrieved in parallel; each phoneme retrieved is labeled as to its ultimate syllabic position. However, for multisyllabic words, each individual syllable is activated in a sequential order. Only some of Dell's models address what happens in multisyllabic words - Dell (1986) is one of them. In contrast, the WEAVER model proposes that the entire phonemic content of a word is activated in parallel (with each phoneme number labeled as to its ultimate position). However, post-phonological processes, such as syllabification of the phonemic string, proceed in a serial manner. Syllabification begins at the first phoneme of the word, and then proceeds sequentially across the phonemes, organizing them into syllabified units which are then used to access the mental syllabary (Roelofs, 1997; Roelofs, 2004; Meyer \& Belke, 2007).

The auditory picture-word interference task may be able to isolate phonological level processes to observe whether begin-related or end-related distractors facilitate naming. If begin-related distractors and end-related distractors produce no difference in phonological facilitation effect across the four distractor onsets, then a parallel view of phoneme ordering would be supported. Alternatively, 
if begin-related distractors facilitate target naming at early onsets and end-related distractors facilitate target naming at later onsets, then a serial pattern of phoneme ordering during retrieval would be supported

\section{Method}

\section{Participants}

The participants were twenty-four non-brain-damaged young controls comprising of seventeen females and seven males ranging in age from 18 to 24 years $(M=20.08$ years). Participants were first year undergraduate psychology students of Victoria University of Wellington who completed the experiment for course credit. All were native speakers of English. An additional five participants were removed because they either did not meet one or more of the selection criteria (aged between 18 to 24 years; English as a first language, normal vision and hearing) or withdrew before completion of the study. Selection criteria were determined by information obtained from a demographic questionnaire (see Appendix B) that requested details about age, language background in English, normal vision and hearing, handedness and history of brain trauma.

\section{Materials}

The stimulus materials used in this experiment were obtained from an unpublished study by Wilshire and Hodgson (2008) ${ }^{1}$. The 96 target words were all bisyllabic words with CELEX lemma frequencies ${ }^{2}$ ranging from 0 to 409 tokens per million (estimated geometric mean 9.88). The pictures used to depict these words were coloured line-drawings and photographs adapted from the Rossion and Pourtois (2004) coloured Snodgrass-like drawings, and a number of other public-domain sources. All pictures yielded name agreement of $80 \%$ or more when piloted on a group of 70 non-brain-damaged speakers of New Zealand English of varying ages. 
Since this experiment formed part of a larger New Zealand/UK collaborative project, picture targets whose familiarity differed widely between British and New Zealand speakers were excluded from the target set (e.g. badger, kiwi). For each target word, two exemplars of each of the following types of distractor words were selected. All distractors were bisyllabic words, and none were semantically related to their targets.

a) Begin-related distractors, in which the distractor word generally shared the same first syllable and stress pattern as the target (e.g., for the target turkey, the begin-related distractors were turnip and turban). (In a small number of cases, where there were no appropriate distractor words, the distractor overlapped by all but the last phoneme of the first syllable, or alternatively, overlapped by the entire first syllable plus the following phoneme). Celex lexeme frequencies for these distractors ranged from 0 to 292 tokens per million (estimated geometric mean 4.40). Over the list considered as a whole, there were no systematic frequency differences between the two exemplars used for each target (estimated geometric means were 4.42 and 4.39 for exemplar sets A and B respectively; paired t-test based on logged corrected frequency values, $p=0.76$ ).

b) Begin-unrelated distractors, which shared no phonemes with the target word e.g., for the target item turkey, begin-unrelated distractors were glider and eyelid). These words were drawn from the same set used to create the beginrelated distractors, randomly repaired with new targets to create unrelated target-distractor pairs.

c) End-related distractors, where the distractor word generally shared the same second syllable and stress pattern as the target (e.g., for turkey, end-related 
distractors were hockey and whiskey). Again, in a very small number of cases, the distractor overlapped by one more or one less phoneme than this, but in most cases it overlapped by the entire second syllable. CELEX lexeme frequencies for these distractors ranged from 0 to 428 (estimated geometric mean 4.82). Over the list considered as a whole, there were no systematic frequency differences between the two exemplars used for each target (estimated geometric means were 4.80 and 4.84 for exemplar sets A and B respectively; paired t-test based on logged corrected frequency values, $p=$ $0.30)$.

d) End-unrelated distractors, which shared no phonemes with the target word. These words were drawn from the same set used to create the begin-related distractors, randomly repaired with new targets to create unrelated pairs (e.g., for pencil, end-unrelated distractors were market and comet).

Finally, there were no significant overall frequency differences between begin-related and end-related distractors (unpaired t-test based on logged corrected frequency values, $p=0.59$ ).

All distractor words were digitally recorded by a speaker of British English.

Design

Each target picture was presented in each of the four types of distractor conditions (begin-related, begin-unrelated, end-related and end-unrelated) at four different distractor-target SOAs: -200 ms, (distractor before target); $0 \mathrm{~ms}$ (simultaneous), $+200 \mathrm{~ms}$ (distractor after target); and $+400 \mathrm{~ms}$. As noted above, there were two exemplars of each distractor type for each target picture, and these were 
alternated across SOAs (e.g. for the target "lemon", the begin-related distractor used at $-200 \mathrm{~ms}$ and $+400 \mathrm{~ms}$ was "leather" and the one used at the other SOAs was "leopard").

Timings were always calculated with respect to the point of overlap between target and distractor. So for example, in the begin-related condition, when the targetdistractor SOA was $+200 \mathrm{~ms}$, this meant that the onset of the first syllable of the distractor was heard $200 \mathrm{~ms}$ after the picture was presented. Conversely, in the endrelated condition, a target-distractor SOA of $+200 \mathrm{~ms}$ meant that the onset of the second syllable of the distractor was heard $200 \mathrm{~ms}$ after the picture was presented. To illustrate, if the distractor word's second syllable began $190 \mathrm{~ms}$ after its onset, presentation of the distractor word would need to commence $10 \mathrm{~ms}$ after the picture, so that onset of the second syllable occurred exactly $200 \mathrm{~ms}$ after the picture. The timings we used in this condition were always word-specific: the duration of each distractor word's first syllable was measured using sound-editing software, and calculated that word's exact presentation time based on that information. For the control conditions, begin-unrelated distractors were presented in exactly the same way as the begin-related distractors, that is, measuring SOA relative to the onset of the first syllable. For the end-unrelated distractors, these were presented in exactly the same way as the end-related distractors, that is, measuring SOA relative to the onset of the second syllable (even though in this condition, there was in fact no overlap between the second syllable of distractor and target).

Since each target picture appeared in 16 conditions (four different distractor conditions $\mathrm{x}$ four different SOAs) and there were 96 target pictures, the total number of trials in the entire experimental design was 1536 . These trials were organised into 16 blocks of 96 trials each, with each target picture appearing once in each block, and 
each block containing a roughly equal number of examples of the various different conditions.

The assignment of items to blocks and blocks to sessions was pseudorandomised to ensure that no individual target-distractor combination was presented more than once in a single session. It also ensured that no more than three successive trials could feature the same distractor condition. The SOA condition was held constant for each target word across blocks in the same session (so for example, in one session, all trials involving the target "lemon" utilised an SOA of -200ms, and in another session, all such trials utilised an SOA of $0 \mathrm{~ms}$, etc.).

Each participant completed 8 blocks of trials spread over two testing sessions (exactly half the total of possible trials). Participants were randomly assigned to one of six different groups, each of which received a different combination of blocks in each of the sessions. Table 2.1 shows the distribution of blocks across the sessions for each group. An equal number of participants were assigned to each group.

Table 2.1.

Distribution of blocks across groups over the two testing sessions

\begin{tabular}{ccccccc}
\hline & Group 1 & Group 2 & Group 3 & Group 4 & Group 5 & Group 6 \\
\hline Session & Blocks & Blocks & Blocks & Blocks & Blocks & Blocks \\
1 & $1-4$ & $1-4$ & $1-4$ & $5-8$ & $5-8$ & $9-12$ \\
\hline Session & Blocks & Blocks & Blocks & Blocks & Blocks & Blocks \\
2 & $13-16$ & $9-12$ & $5-8$ & $9-12$ & $13-16$ & $13-16$ \\
\hline
\end{tabular}




\section{Procedure}

The experiment was run on a Macintosh iMac computer using PsyScope software (Cohen, MacWhinney, Flatt, \& Provost, 1993). The auditory distractors were presented over two external speakers placed on both sides of the computer screen. All sessions were recorded on digital minidiscs.

At the start of the first session, participants were provided with an information sheet outlining brief details of the study. Participants gave signed consent before proceeding and were advised that they could withdraw from the study at any stage if they felt uncomfortable to continue. Participants also filled in the demographic questionnaire at the same time.

Participants were tested individually over three sessions that were spaced at least three days apart. The first session consisted of a pre-test naming task, in which all 96 stimulus pictures were presented for naming. Pictures were presented in a random order preceded by 4 practice items. Each picture stimulus remained visible until the participant completed their response.

They were asked to name all items as quickly and as accurately as possible. The pre-test session was carried out to familiarise participants with the stimulus pictures for the experiment (and also to provide a baseline naming latency data for each picture, which could then be used if required in subsequent analyses). In the pre-testing session, if the participant gave a non-target word, the target word was provided. In subsequent sessions, the participant was not corrected.

In the experimental sessions, participants were told to name the pictures and ignore the distractor words. When the participant was ready, the experimenter pressed a key to commence the trial. A welcome screen with instructions first appeared. The information was centred in black font against a white background. The participant 
then pressed the spacebar to continue and a single trial proceeded as follows. The key press was accompanied by a 'beep' indicating the start of the trial. Then $700 \mathrm{~ms}$ later, the picture stimulus appeared. The onset of the auditory distractor varied according to SOA condition (either $-200 \mathrm{~ms}, 0 \mathrm{~ms},+200 \mathrm{~ms}$ or $+400 \mathrm{~ms}$ ). The picture remained on the screen throughout the naming attempt. See Figure 1.4 for a layout of the current study.

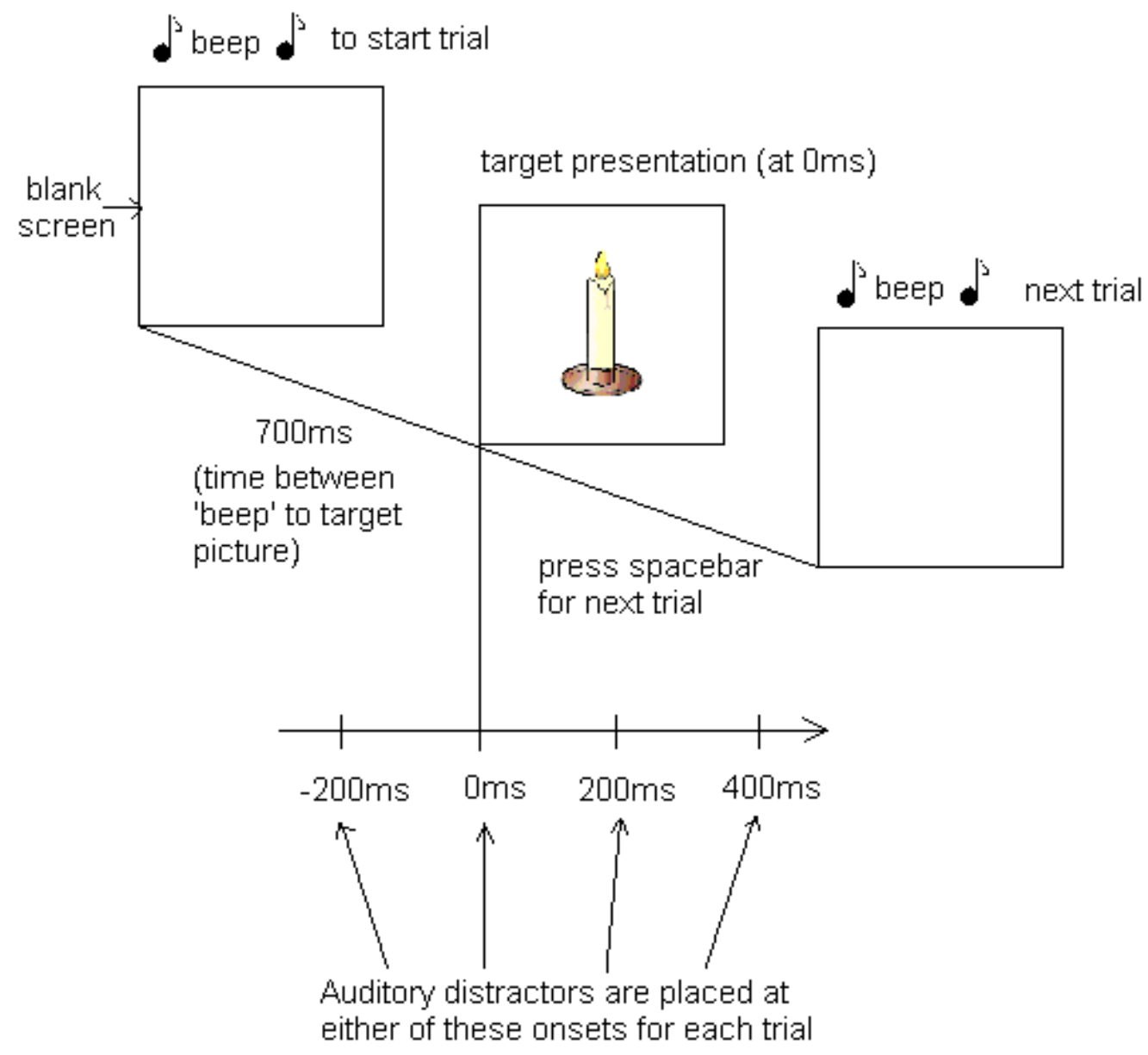

Figure 1.4. A layout of the auditory picture-word interference task in the current study 
During these experimental sessions, participants completed four entire blocks of items with breaks at the end of blocks 1,2 and 3. These breaks were indefinite and ended when the participant pressed a key to commence to the next block of trials. Each block commenced with four practice items. Participants were reminded of the task instructions at the end of blocks 1 and 3 and they were debriefed at the end of the third session.

\section{Data and Statistical Analysis}

Multiple attempts at pictures were allowed. All responses (whether correct or incorrect) were noted. Naming latencies for correct responses were manually measured using digital sound analysis software, measuring from the onset of the target picture to the onset of the first correct naming response (if there was one).

All error responses were removed for separate analyses. Latencies for correct responses made for picture targets that elicited three or more errors across all sessions for any subject were also removed from the data for that subject. Finally, outliers that were 2.5 standard deviations above the participants' grand mean latency were also removed $^{3}$ (see Ratcliff, 1993)

The resultant data set was submitted to a General Linear Mixed Model analysis (or "mixed effects" model). This method of analysis enables the researcher to incorporate more than one random effect, a feature that is useful for the analysis of multiple-participant, multiple-item data (see Diggle, 1988; for applications to psycholinguistic data, see Baayen, Davidson \& Bates, 2008). The model incorporated two random effects - participant name and target picture name. 


\section{Results}

A small proportion of data points were lost due to technical issues caused by failure of recording equipment or the software. These made up a total of $0.27 \%$ of the total data points.

Accuracy Analysis

The younger controls performed very accurately on this task. As a group, they correctly produced $96.8 \%$ of the targets in the begin-related condition, compared to $96.0 \%$ of the targets in the begin-unrelated condition. A Chi squared test revealed a marginally significant difference between these two values, $\chi^{2}(1)=3.77, p=0.052$. For the end related condition and its unrelated control, the percentages of targets correctly named were $96.0 \%$ and $96.5 \%$ respectively. Chi squared tests revealed no significant differences between these two conditions, $\chi^{2}(1)=1.45, p=0.23$. Table 2.2 shows the total errors produced across the various SOAs and distractor conditions. Figure 2.1 plots the differences in error totals between each phonologically related condition and its respective control condition separately for the four SOAs. On the left side of this figure (based on observation alone), the difference between the beginrelated condition and begin-unrelated condition appears to elicit a positive value, which suggests that more errors were made in the unrelated condition compared to the begin-related condition. On the right side, there appears to be an inhibitory response from the end-related distractors as they produced more errors compared to the end-unrelated distractors. 
Word Form Retrieval in Spoken Word Production

Table 2.2.

A tally report of the total number of outright naming errors and omissions made across the different distractor and SOA conditions

\begin{tabular}{cccccc}
\hline & & \multicolumn{2}{c}{ Target } & SOA (ms) & \\
\cline { 2 - 5 } Condition & -200 & 0 & 200 & 400 & Total \\
\hline Begin-related & 40 & 39 & 28 & 41 & 148 \\
Begin unrelated & 55 & 47 & 44 & 38 & 184 \\
End-related & 59 & 43 & 38 & 42 & 182 \\
End unrelated & 43 & 45 & 36 & 35 & 159 \\
\hline
\end{tabular}




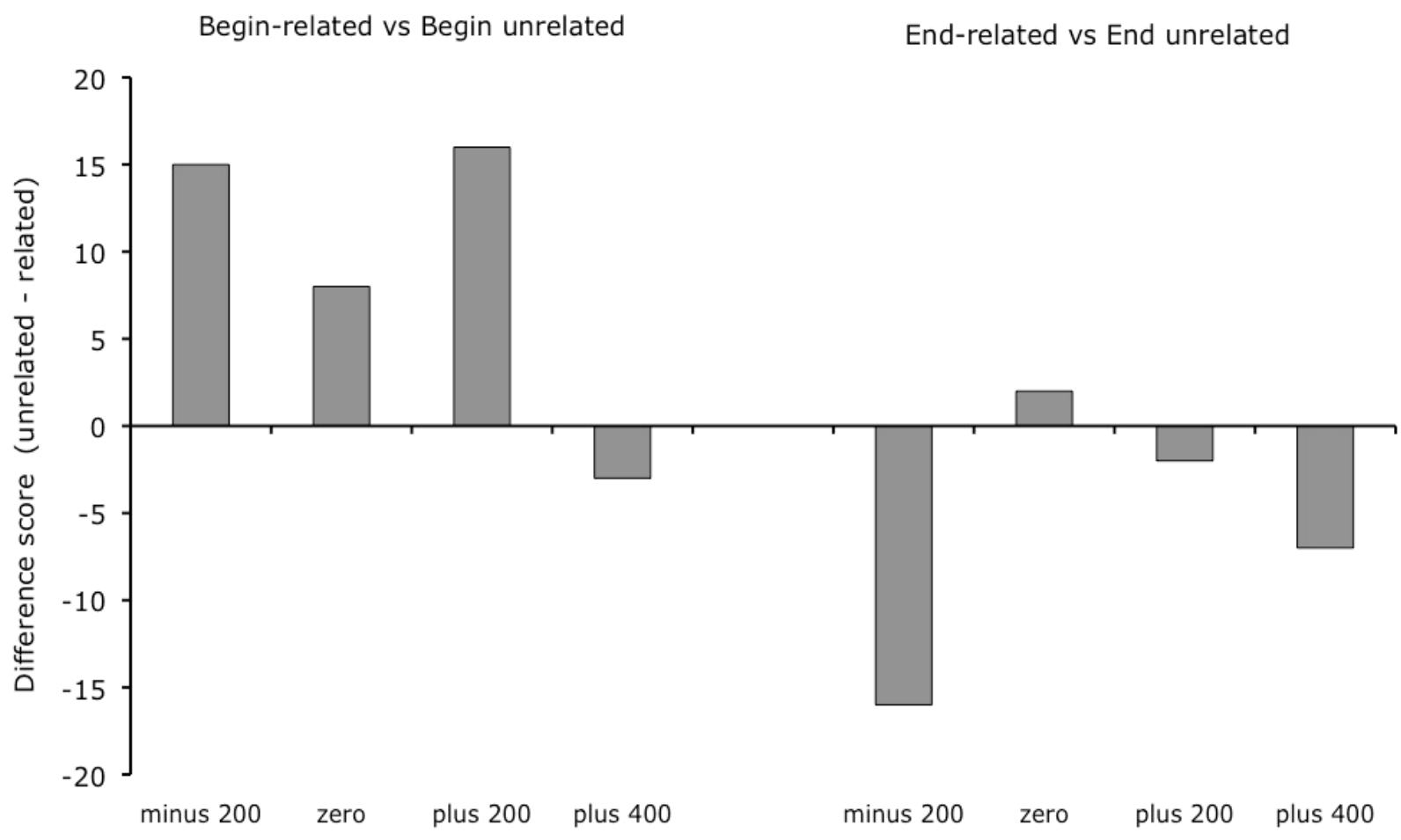

Figure 2.1. The difference of the total incidence of error between the phonologically related conditions (begin-related and end-related) and their respective unrelated controls. A positive difference score indicates fewer errors in the related condition than its respective control; a negative difference indicates the opposite. 
Turning now to the nature of errors, of the 673 trials that were failed, $93.7 \%$ (631) were substitutions of semantically related words (e.g., responded "teapot" instead of kettle; "pendant" instead of locket), 0.9\% (6) were formal paraphasias (e.g., "cannon" instead of camera; "magnet" instead of marble) and 5.3\% (36) were caused by other errors or failures to respond. Appendix $\mathrm{C}$ shows a detailed report of the different types of outright naming errors made across the different distractor and SOA conditions.

Naming Latency Analysis

Prior to analysis of latency data, the following pruning procedures were applied. First, latencies where participants produced three or more fails on the target across all their sessions were removed. This resulted in a loss of $1.03 \%$ of the data. Second, outliers, defined as responses that were 2.5 standard deviations above the mean, were also removed resulting in a further loss of $2.91 \%$ of trials. Upon analysis of the raw data, an excessively positive skew was observed (skew value: 1.89). Values greater than 1 suggest a very positively skewed distribution where zero is a normal distribution. Therefore, the naming latency data were log transformed prior to analysis (in order to normalise the distribution curve towards the zero or normal range) producing a new skew value of 0.92 .

Table 2.3 shows the geometric mean naming latencies to correct responses for the young controls across SOAs and distractor conditions. Figure 2.2 shows the percentage difference in latency between each phonologically related condition and its respective control for each of the four SOAs. As can be seen, the related conditions tended to elicit faster latencies than their unrelated controls. For the first three SOAs $(-200 \mathrm{~ms}, 0 \mathrm{~ms}$ and $200 \mathrm{~ms})$, the difference in latencies between related and control conditions tended to be greater for the begin-related than for the end- 
related distractors. The most marked differences between begin and end conditions can be observed at the SOAs of $0 \mathrm{~ms}$ and 200ms. However, at an SOA of 400ms, the end-related effect appears to be slightly larger than the begin-related effect.

Table 2.3.

Geometric mean naming latencies of correct responses across the four distractor conditions and SOAs (figures in brackets are the values that lie one standard deviation below and above the mean respectively). ${ }^{4}$

Target SOA

\begin{tabular}{lcccc} 
& $-200 \mathrm{~ms}$ & $0 \mathrm{~ms}$ & $+200 \mathrm{~ms}$ & $+400 \mathrm{~ms}$ \\
\cline { 2 - 5 } Condition & $688(532,890)$ & $654(451,809)$ & $658(463,808)$ & $681(492,829)$ \\
\hline $\begin{array}{l}\text { Begin- } \\
\text { related }\end{array}$ & & & & \\
$\begin{array}{l}\text { Begin- } \\
\text { unrelated }\end{array}$ & $709(503,869)$ & $719(512,879)$ & $702(481,870)$ & $688(491,841)$ \\
$\begin{array}{l}\text { End- } \\
\text { related }\end{array}$ & $670(480,820)$ & $680(496,825)$ & $694(502,844)$ & $696(492,854)$ \\
& & & & \\
$\begin{array}{l}\text { End- } \\
\text { unrelated }\end{array}$ & $674(492,817)$ & $695(509,842)$ & $704(505,859)$ & $713(487,884)$ \\
\hline
\end{tabular}




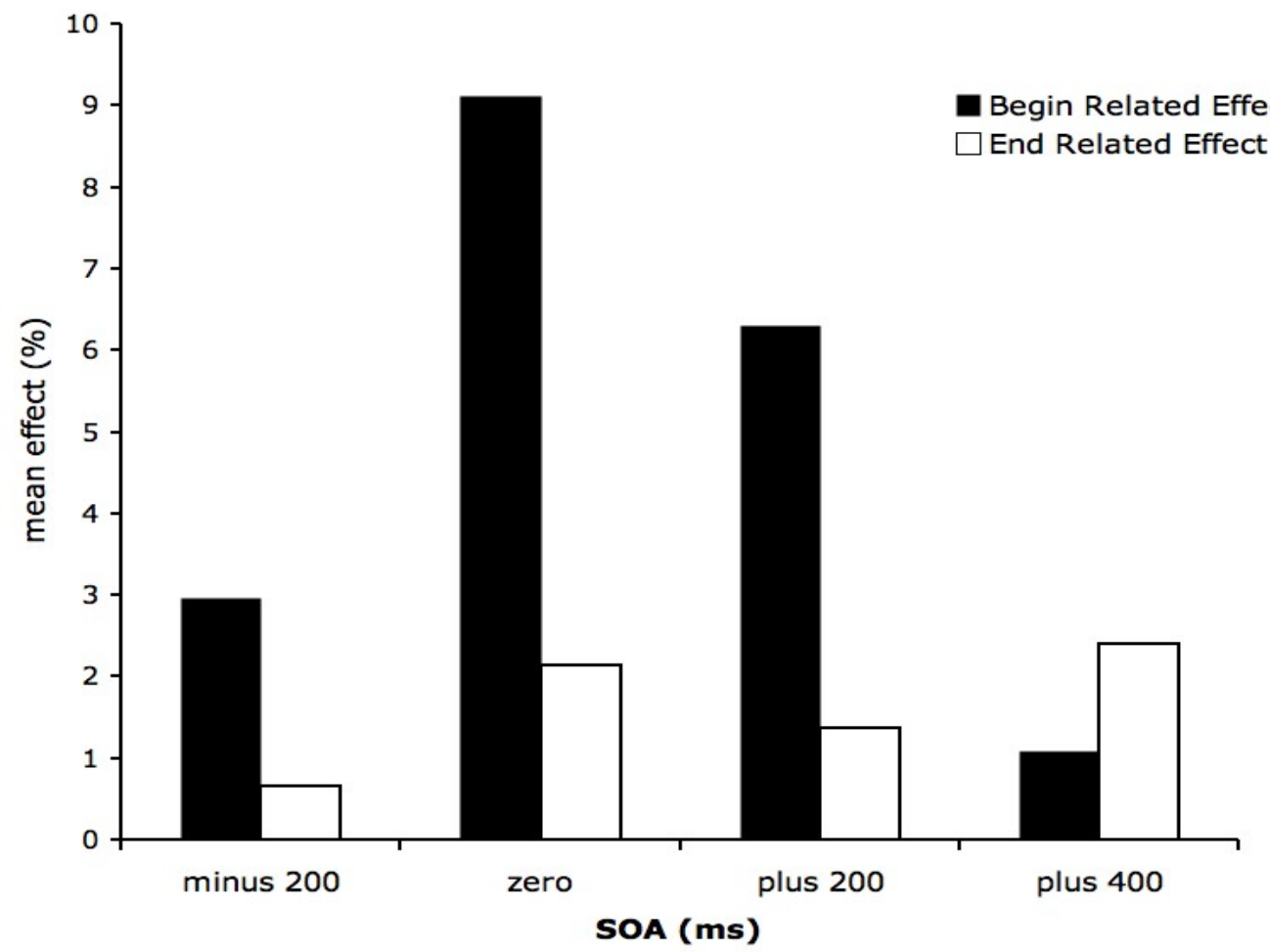

Figure 2.2. The percentage difference in latency between each phonologically related condition and its respective control for each of the four

SOAs are displayed. The values displayed were obtained by first subtracting the geometric mean latency of the phonologically related condition (begin-related or end-related) from its respective unrelated control, then expressing this difference as a percentage of the latter value. 
A general linear mixed model analysis of the latency data incorporating both participants and target names as random effects, revealed a significant main effect of distractor type, $F(3,17000)=32.81, p<0.0001$, and of SOA, $F(1,17000)=14.61$, $p<0.0001$, and a significant distractor type by SOA interaction, $F(3,17000)=17.79$, $p<0.0001$. Planned comparisons revealed a significant main effect of begin-relatedness (begin-related vs. begin-unrelated), $F(1,17000)=89.30, p<0.0001$. This effect also interacted significantly with $\mathrm{SOA}, F(1,17000)=4.54, p<0.05$. There was also a significant main effect of end-relatedness (end-related vs. end-unrelated), $F(1,17000)=$ 7.31, $p<0.05$, but no interaction between this effect and SOA, $F(1,17000)=1.45, p$ $>0.05$. Pairwise comparisons revealed a significant begin relatedness effect (beginrelated vs. begin-unrelated) at all four SOAs ( $p<0.0001$ at all four onsets) as well as significant effects of end-relatedness at $0 \mathrm{~ms}(p<0.05), 200 \mathrm{~ms}(p<0.001)$ and $400 \mathrm{~ms}$ $(p<0.01)$, but not at the earliest onset of $-200 \mathrm{~ms}$.

\section{Discussion}

Begin-related distractors significantly facilitated target picture naming compared to the corresponding unrelated distractors at all four distractors onsets (SOAs). The difference in facilitatory effects across the four SOAs also reached significance suggesting that the size of the facilitatory effects were dependent on SOA (see also Schriefers et al., 1990). The most marked facilitatory effect of begin-related distractors was observed at $0 \mathrm{~ms}$, at the time of picture presentation. The next most prominent facilitatory effect was observed at the onset of $200 \mathrm{~ms}$ after picture presentation. This pattern of facilitation is consistent with previous studies that investigated phonological facilitation effects using begin-related distractors (e.g. Schriefers et al, 1990; Meyer \& 
Schriefers, 1991; see also Damian \& Martin, 1999; Starreveld, 2000; Taylor \& Burke, 2002).

There are several possible explanations for these findings. At 0ms, when the target picture is presented, the largest facilitatory effect is observed. This may be attributable to shared phonological segments between the target and distractor activating the target's lexical representation through feedback activation (Damian \& Martin, 1999; Foygel \& Dell, 2000). Therefore, the time needed for phonological encoding of the target is reduced. At $200 \mathrm{~ms}$ after picture presentation, begin-related distractors may be affecting processes happening at the phonological and or lexical stage (Wilshire et al., 2007). It could also be that all these distractors are influencing the same stage of processing, but there are subtle differences between trials and how long it takes to get to that stage. There is constant debate as to whether distractors interfere with processes happening at the phonological level or lexical level. These will be discussed in further detail below. Although a significant facilitation effect was observed at $-200 \mathrm{~ms}$, it was still much smaller than the effect at $0 \mathrm{~ms}$ onset. This finding may suggest that presentation of the distractor may have been too early so phonological and potentially lexical representations that became activated by the distractor started to decay (Meyer \& Schriefers, 1991). However, it is possible that these representations are substantially active at this stage as they would have been if the distractors were presented at $300 \mathrm{~ms}$ to $400 \mathrm{~ms}$ before the target, so the begin-related distractor may still able to facilitate target naming to some extent at this SOA. At $400 \mathrm{~ms}$ and potentially later SOAs in general, facilitatory effects start to diminish (Schriefers et al., 1990; Meyer \& Schriefers, 1991; Starreveld, 2000; Wilshire et al., 2007). Even though our data shows significant 
facilitatory effects at this SOA; by observation of the mean effects alone, facilitation levels appear to be notably low compared to other SOAs.

It is possible that the begin-related effect may not only be attributable to facilitatory effects of the begin-related distractors alone but alternatively to the interfering or competitive effects produced by the corresponding unrelated distractors. The placement of unrelated distractors potentially activates different lexical representations to the target. This in turn leads to a competition for selection between the target and distractor's lexical representations rather than facilitation (Damian \& Martin, 1999; Taylor \& Burke, 2002; Wilshire et al., 2007). This may especially be the case when the unrelated distractor is placed close to the timing of picture presentation or at SOAs where begin-related distractors produce the greatest facilitatory effects (i.e. $0 \mathrm{~ms}$ and $200 \mathrm{~ms}$ ). A possible approach to test for this competition would be to compare reaction times on the naming task between the unrelated distractor condition with a simple noise condition; or perhaps a silent (no distractor) condition ${ }^{5}$. Wilshire et al. (2007) argued that the distractor's lexical representation does not receive additional top down activation from the semantic level so it never becomes substantially active to compete with the target for phonological encoding.

There is also the possibility that these unrelated distractors might have been exerting an interfering effect at the phonological level during encoding. This brings us back to the previous discussion about whether distractors interfere with processes happening at the phonological level or lexical level. Some researchers argue that beginrelated distractors facilitate production of the target by exerting their effects at the lexical level (Wilshire \& Saffran, 2005; Wilshire et al., 2007); some argue for distractor effects 
at the phonological level (Schriefers et al., 1990; Meyer \& Schriefers, 1991; Roelofs, 1997; Roelofs, 2004) or some argue for both (Damian \&Martin, 1999; Starreveld, 2000). Wilshire et al. (2007) refuted the idea that distractors exert their effects at the phonological level and argued that if this were the case, then one would expect to see phonological facilitation happening at later SOAs. This idea would work best on the assumption that lexical access occurs around the time of picture presentation and phonological encoding soon after. At this point, we have no absolute predictions about the exact onsets that are most effective under the two models. Several studies including the current one did not find late phonological facilitation effects, which supports their argument.

The end-related distractors produced small but significant phonological facilitation effects on the naming task compared to their corresponding unrelated distractors at 0ms, 200 and 400ms SOAs but not at the earliest onset of -200ms. It was interesting to observe that this end-relatedness effect did not vary significantly across all onsets and the strongest effect was at $400 \mathrm{~ms}$, which was bigger than the begin-related condition on observation alone. Also, end-related distractors produced significant but relatively smaller phonological facilitation effects at $0 \mathrm{~ms}$ and $200 \mathrm{~ms}$ compared to beginrelated distractors. Similar results were found previously by Meyer and Schriefers (1991) who initially argued that both distractor conditions should elicit the same pattern of facilitation according to the WEAVER model. However, they observed that end-related distractors produced facilitatory effects at later distractor onsets though these effects were not significant. This finding provides evidence towards the idea that phonological encoding of end syllables of the target word occurs later compared to initial syllable(s). 
As mentioned previously, according to the WEAVER model, these end-related distractors would be exerting their effects at the phonological encoding stage. However, if this were the case, we would expect to see late phonological facilitation effects. Hence, their findings would probably be suited to the two-step model to account for end-related phonological facilitation effects. The two-step interactive activation model is also able to account for the current findings of significant facilitation effects for end-related distractors at $0 \mathrm{~ms}, 200 \mathrm{~ms}$ and $400 \mathrm{~ms}$ SOAs.

So what does this tell us about the phoneme retrieval process? As observed in the current study and in previous studies on facilitation effects using the same picture-word interference paradigm, we observed begin-related distractors having strong significant facilitation effects at earlier SOAs and end-related distractors having significant facilitation effects at later SOAs. This suggests that processing of initial phonemes is happening at an earlier stage of phonological encoding followed by later phonemes which provides evidence towards a serial view of phoneme retrieval. Furthermore, the evidence of begin-related distractor effects on the time course of word production support a theory of lexical access as suggested by an interactive model of word production.

This first phase has provided evidence for a serial pattern of phoneme retrieval during phonological encoding amongst young, normal functioning individuals. However, would we find these same patterns of facilitation and serial phoneme ordering in an older, normal population? Additionally, would we see the same effects in an aphasic individual? If not, what would we expect to find and what can we say about the phoneme ordering process amongst individuals with language deficits? The next chapter investigates the 
Word Form Retrieval in Spoken Word Production

phoneme ordering process amongst older non-brain damaged individuals and a person with aphasia using the same auditory picture-word interference task. 


\section{CHAPTER THREE}

PHASE TWO: The auditory picture-word interference task with older controls and an aphasic case study

\section{Introduction}

The results from the first phase of this study have highlighted some important aspects of word production. The most important finding was that the picture naming process was facilitated when auditory distractors presented shared phonological segments to the target. Begin-related distractors showed significantly strong facilitation at all SOAs with effects peaking at $0 \mathrm{~ms}$ followed by $200 \mathrm{~ms}$ onsets. End-related distractors also showed significant facilitation effects when presented at later onsets but these were relatively weaker in comparison to those of begin-related distractors. End-related distractors however had a stronger facilitatory effect at the SOA of 400ms compared to begin-related distractors. These findings provided evidence towards a serial view of phoneme retrieval where initial syllables become available first before later ones.

In this next phase of the study, we investigate the same auditory picture-word interference task on a different group of participants. We investigate a group of older controls as well as an aphasic individual, NP to see if they would produce similar patterns of facilitation to the participants in the previous phase of this study. These findings would be used to deduce whether the phoneme ordering process is consistent with age differences. Also, we are interested to know how the phoneme ordering process is affected in an individual with a language deficit.

Burke and Shafto (2004) observed that the ability to produce words declines with age. They argued that connections between lexical and phonological units within word 
production models weaken with age, so processes like retrieving sound information of a word to be articulated are affected. However, they also observed that in the majority of older individuals, access to semantic information was barely affected. Word finding failures appear in different forms, a predominant one being the 'tip-of-the-tongue' effect (TOT; Burke \& Shafto, 2004). James and Burke (2000) observed reduction in TOT and faster naming latencies on target naming amongst older individuals when phonologically related distractors were used. They suggested that the phonologically related words strengthened weak connections between lexical and phonological units that caused TOT and reduced naming latencies. Taylor and Burke (2002) observed the same pattern of phonological facilitation for begin-related distractors across similar SOAs used in the current study between older and younger individuals. Therefore, in the current study, we would expect to see relatively faster naming latencies in conditions that use begin-related or end-related distractors as opposed to unrelated distractors for the older controls. Additionally, we would expect to see the same pattern of phonological facilitation for begin-related distractors for the older control group as observed in phase one. However, the end-related distractors may not produce strong facilitation effects due to weakened connections between phonological and lexical units. These potential differences mean that we cannot compare our group of young controls directly to an aphasic speaker's performance on the auditory picture-word interference task. Instead, we will have to compare performance to an older group of non-brain damaged controls to rule out any extraneous effects of age.

We are interested in finding out more about the phoneme ordering process through phonological facilitation effects on an aphasic individual using the auditory 
picture-word interference task. There have only been a few studies that look at facilitation effects in this task using an aphasic population (e.g. Wilshire \& Saffran, 2005;

Wilshire et al., 2007). As the locus of impairment in an aphasic speaker is generally known from prior independent testing, we may be able to attribute abnormalities in performance on the task to the identified malfunctioning stage(s) of processing. Wilshire and Saffran (2005) looked at phonological facilitation effects and overall accuracy scores using begin-related and end-related distractors on two fluent aphasic individuals. They found that each aphasic speaker responded differently to the distractors where one's naming latencies were facilitated by begin-related distractors whereas the other's naming latencies were facilitated by end-related distractors. They did not look at facilitation effects across different SOAs and suggested that their findings supported the idea that begin-related distractors and end-related distractors operate at different stages within a two-stage model of word production. They also suggested that a serial view of phoneme retrieval would support their results. The current study follows on from Wilshire et al. (2007) which looked at facilitation effects of only begin-related distractors at the same SOAs used in the current study. They found significant phonological facilitation effects on picture naming latencies for begin-related distractors at $-200 \mathrm{~ms}, 0 \mathrm{~ms}$ and $200 \mathrm{~ms}$ SOAs for their aphasic speaker NP (who is also tested in the current study) whereas these effects failed to reach significance for the control group. In addition, they also found these effects to be of greater magnitude for NP compared to the control group.

Picture naming is a fairly automatic and rapid process for normal functioning individuals so any distractor effects present may be too small to elicit clear observations of the phoneme ordering process during phonological encoding (Wilshire \& Saffran, 
2005; Hashimoto \& Thompson, 2010). Aphasic individuals show deficits in the pictureword interference task as observed by their exaggerated facilitation effects, significantly slower naming latencies as well as frequent word finding pauses (Wilshire \& Saffran, 2005; Wilshire et al., 2007; Hashimoto \& Thompson, 2010). By examining the manner in which phonemes are retrieved through phonological facilitation effects, we may be able to isolate and identify which stage(s) of word production are disrupted within this population (Wilshire \& Saffran, 2005; Hashimoto \& Thompson, 2010).

Previous studies have shown begin-related distractors to produce pronounced facilitation effects in individuals with lexical impairment compared to individuals with phonological impairment. This finding suggests an involvement of the lexical level for the phonological facilitation effect (e.g. Wilshire \& Saffran, 2005; Wilshire et al., 2007; Hashimoto \& Thompson, 2010). In a two-stage model of word production, impairment at the lexical stage would result in semantic errors whereas impairment at the phonological stage would result in phonological errors (Wilshire \& Saffran, 2005). Dell et al.’s (1997) interactive model suggests that in cases where activation to the lexical level is relatively weak, the target's lexical node may not be activated enough to compete with other semantically related nodes (that also receive some activation). This may result in semantic errors as a competing node wins over the target. In a situation where activation to the phonological encoding stage is weak, there is the possibility that some of the phonemes of the target word may not be activated resulting in phonological errors (Wilshire \& Saffran, 2005).

Wilshire et al. (2007) argued that NP has slow transmission of activation from the semantic to lexical level, and was therefore diagnosed with a primary deficit in lexical 
selection. The auditory picture-word interference task may be able to provide us with information on the time course of phonological facilitation for NP and the older control participants (Wilshire et al., 2007). From findings in the previous related study (i.e. Wilshire et al., 2007), we would expect to see a similar pattern of facilitation for beginrelated distractors for the groups in this phase of the study. We would also expect to observe exaggerated facilitation effects of begin-related distractors across all SOAs for NP (Wilshire \& Saffran, 2005; Wilshire et al., 2007; Hashimoto \& Thompson, 2010). There could potentially be slight variations in findings this time as distractor frequencies have been tightly controlled. Loosely matched distractor frequencies were previously thought to have contributed to the reduced facilitation effects previously observed (Wilshire et al., 2007). Another potential contributor to a change in phonological facilitation effects in the current study for NP is time. Wilshire et al. (2007) carried out this task on NP in 2005. His performance may have improved since through rehabilitation processes or it could have worsened since the last testing due to possible weakening of lexical and phonological connections with age (Burke \& Shafto, 2004).

It is hard to predict the phonological facilitation effects of end-related distractors on NP for several reasons. First, there is limited literature that employs the auditory picture-word interference paradigm with aphasic populations. Second, there may be potential differences in findings from controls in the first phase of this study as a result of age. Lastly and most importantly, the high variability between cases of people with aphasia due to the locus of impairment may produce different results from findings in previous studies. 
Case Description (from Wilshire et al., 2007)

The following information provided is a summary of important language processing attributes of NP relevant to the current study. For a comprehensive description of NP's condition and test performance, refer to Wilshire et al (2007).

NP is a retired 71 year old who suffered a CVA in August 1999. A CT scan conducted at that time revealed reduced attenuation in the left hemisphere, including the occipital lobe, the basal ganglion and the temporal lobe. During initial diagnosis at that time, NP presented with right homonymous hemianopia, right hemiplegia, right neglect and expressive aphasia. He was first tested in 2003, and at that time his speech was fluent but rather empty, word-finding pauses, and some occasional phonemic paraphasias (see Table 3.1 for a speech sample).

Table 3.1.

Patient NP's description of the Cookie Theft picture from the Boston Diagnostic Aphasia Examination (Goodglass \& Kaplan, 1983). This table has been taken from Wilshire et al (2007)

"First of all he. . . he's falling off the. . the. . um, stool. . he- he- he's keep- he's helping himself the // the biscuits that he's passing down, but it be. . /s/// the. . the stool. And. . uh mum has. . forgot to turn the- water off the tap and so it's. . I/ everywhere. She's- mum is. . drying the- the dishes. . she's drying uh- the dishes. . um. . but I don't know how she's /s-/. . I don't know why she's stand there so bloody long with the. . pour all uh. . pour all over her (laugh). . but she is." 
On the Boston Diagnostic Aphasia Examination (Goodglass \& Kaplan, 1983), NP was diagnosed with anomic aphasia: he showed mild impairment through his comprehension scores and repetition scores. His auditory single-word comprehension was relatively well preserved but he showed a mild to moderate impairment on auditory or phonological input processing tasks. On the PALPA phoneme discrimination task (Kay, Lesser \& Coltheart, 1992), performance was in the low to normal range, and on the PALPA auditory lexical decision test, his score was just outside the normal range (consistent with a mild impairment in processing auditory phonological material). NP's performance on the Boston Naming Test (Goodglass \& Kaplan, 1983) was well outside the range for age-matched controls (Cruice,Worrall \& Hickson, 2000) and he also made a considerable amount of errors on the Wilshire Length and Frequency Naming Test (Wilshire, 2002).

Frequency appeared to be a particularly strong determinant of performance on the Wilshire Length and Frequency Naming Test (scores ranged from 55\% on low frequency items to $87 \%$ on high frequency items). As can be seen in Table 3.2, the vast majority of NP's errors on this task were whole word substitutions: of these the most common were semantic paraphasias (ostrich instead of "peacock"; camel instead of "giraffe") followed by unrelated word substitutions (e.g., hammock instead of "igloo"; scarecrow instead of "hedgehog") and mixed errors (e.g., cannon instead of "gun"; cherry instead of “raspberry”). There were also some occasional phonemic paraphasias. 
Word Form Retrieval in Spoken Word Production

Table 3.2.

Performance of patient NP on standard language tests. Table taken from Wilshire et al (2007)

Name of test

Score

Comprehension and semantic processing

Philadelphia comprehension battery (Saffran et al., 1988)

Word-picture matching - within category $\quad 16 / 16$

Word-picture matching - across category 28/28

Synonymy judgment $27 / 28^{\text {a }}$

Sentence comprehension (Set A) $\quad 59 / 60$

Peabody Picture Vocabulary Test Form IIIA (Dunn \& Dunn,1987) 155/204

Pyramids and Palm Trees (Howard \& Patterson, 1992): three $\quad$ 49/52 picture subtest

Auditory language processing

PALPA Test 2: same-different discrimination of word pairs $\quad 65 / 72$

PALPA Test 5: auditory lexical decision $\quad$ 132/160

Picture naming

Boston Naming Test (Goodglass \& Kaplan, 1983) 33/59

Wilshire Length and Frequency Naming Test (Wilshire, 2002) 123/180

Word and nonword repetition

Repetition of Wilshire Length and Frequency Naming Test words $138 / 180$

$\begin{array}{ll}\text { PALPA Test 8: nonword repetition } & 12 / 30\end{array}$ 
Serial recall

PALPA Test 13: auditory digit repetition span (span estimate) $\quad 4$

Numbers indicate total items correct unless otherwise indicated. Note: PALPA:

Psycholinguistic Assessment of Language Processing in Aphasia (Kay et al., 1992).

a. Total is out of 28, not 30, because two US English items were not administered.

b. Total is out of 59, not 60, because one US English item was not administered.

NP's repetition of the words from the Wilshire Length and Frequency Naming

Test was significantly more accurate than his naming of the same items. On this

repetition test, NP showed a significant reverse length effect, scoring better on bisyllables

and polysyllables ( $87 \%$ in both cases) than on monosyllables (57\%). There was also a

significant effect of frequency. As shown in Table 3.3, the vast majority of NP's errors on this task were formal paraphasias (e.g., kite instead of "height"; frog instead of "rod";

button instead of "butter"). Finally, auditory and visual digit span tasks revealed a

moderately reduced digit span in NP. On the PALPA auditory digit repetition task, his

span estimate (longest length on which the majority of sequences were correctly recalled)

was four. 
Word Form Retrieval in Spoken Word Production

Table 3.3.

Patient NP: breakdown of responses on Wilshire Length and Frequency Naming Test (2002), and its corresponding repetition test. Table taken from Wilshire et al (2007)

\begin{tabular}{lcc}
\hline \multirow{2}{*}{ Response type } & \multicolumn{2}{c}{ Percentage of total responses } \\
\cline { 2 - 3 } & Naming & Repetition \\
\hline Correct & 68.3 & 76.7 \\
Phonemic paraphasia & 3.9 & 5.6 \\
Formal paraphasia & 1.7 & 10.6 \\
Semantic paraphasia & 6.1 & 0 \\
Unrelated word & 5.6 & 0 \\
Mixed error & 5.0 & 0 \\
No response & 4.4 & 4.4 \\
Other & 5.0 & 2.8 \\
\hline
\end{tabular}

NP's performance on standard language tests indicates a selective difficulty with word production. His naming is mildly to moderately impaired, and most of his errors are semantic and other whole word substitutions. In contrast, performance on word comprehension tasks which include the Philadelphia Comprehension Battery is relatively well preserved. Only one task, the Peabody Picture Vocabulary Test, indicated slightly lower scores. Within a two-stage model of word production, NP's profile is consistent with a primary impairment at the lexical selection stage. Also consistent with this account are the word frequency effect in naming. Nevertheless, there is also some indication of a 
mild auditory-phonological input-processing deficit: NP was mildly impaired on tests of phonological discrimination and auditory lexical decision. Also, repetition tasks exhibited reverse length effects and elicited high rates of formal paraphasias - both features that have been associated with a phonological input-processing problem (see, e.g., Wilshire \& Fisher, 2003). There is also some suggestion of a mild phonological encoding impairment: NP made occasional phonemic paraphasias in naming and performed better on short than on long words. But again, this problem would appear to be mild, particularly in comparison to his word selection difficulty.

\section{Method}

\section{Participants}

The participants were NP and six non-brain-damaged older controls comprising of four females and two males ranging in age from 60 to 70 years $(M=64.67$ years). The selection criteria were identical to part one with the exception that the older control participants had to be aged between 60 and 70 years. The same demographic questionnaire used in part one was carried out with the controls to check for these details (i.e. normal or corrected vision and hearing). The older controls were either currently working or retired professionals who were all native speakers of English. They completed the experiment for monetary rewards.

\section{Materials}

\section{Design \\ Materials in this part were identical to phase one.}

The design used was identical to phase one with the following exception. Each participant completed all 16 blocks of trials. These were spread over four testing sessions for the older controls with each participant completing 4 blocks of trials each session. 
For NP however, the blocks were spread over eight testing sessions (two blocks per session).

Procedure

The procedure used here was identical to phase one. The older control participants were debriefed at the end of the fifth session. Due to NP's inability to travel to the university, testing took place at his home using a MacBook laptop. Sound and display settings were kept identical to phase one. NP was debriefed at the end of the eighth session.

\section{Data and Statistical Analysis}

Data were analysed in the same manner as in part one. The control participants were analysed separately from NP. As NP was the only participant in his group, the analysis for this part incorporated only one random effect: target name. Furthermore, results produced from the older participants and NP were compared to one another to identify other possible trends that may have been missed if each group were kept isolated.

\section{Results}

A small proportion of data points for the older controls and NP were lost due to technical issues caused by failure of recording equipment or the software. These made up a total of $0.04 \%$ of the total data points for the controls and $0.13 \%$ for NP. Accuracy Analysis

The older controls performed very accurately on this task. As a group, they correctly produced $99.3 \%$ of the targets in the begin-related condition, compared to $99.0 \%$ of the targets in the begin-unrelated condition. A Chi squared test revealed no significant difference between these two values, $\chi^{2}(1)=1.3, p=0.25$. For the end related 
condition and its respective unrelated control, the percentages of targets correctly named were $99.4 \%$ and $99.2 \%$ respectively. Chi squared tests revealed no significant differences between these two conditions, $\chi^{2}(1)=0.52, p=0.47$. NP also performed reasonably accurately on this task. He correctly produced $92.4 \%$ of the targets in the begin-related condition, compared to $84.9 \%$ of the targets in the begin-unrelated condition. A Chi squared test revealed a significant difference between these two values, $\chi^{2}(1)=10.01, p$ $<0.001$. For the end related condition and its respective unrelated control, the percentages of targets correctly named were $86.4 \%$ and $87.0 \%$ respectively. Chi squared tests revealed no significant difference between these two conditions, $\chi^{2}(1)=0.02, p=$ 0.89. Table 3.4 shows the total errors produced across the various SOAs and distractor conditions for both the control group and NP. A brief review of this table suggests NP performed more accurately in the begin-related condition compared to the beginunrelated condition. Although an opposite pattern is observed for the end-related and end-unrelated condition, this effect is not significant. 
Word Form Retrieval in Spoken Word Production

Table 3.4.

A tally report of the total number of outright naming errors and omissions made across the different distractor and SOA conditions for the older controls and NP

\begin{tabular}{|c|c|c|c|c|c|c|}
\hline \multirow[b]{2}{*}{ Participant } & \multirow[b]{2}{*}{ Condition } & \multicolumn{4}{|c|}{ Target $\mathrm{SOA}(\mathrm{ms})$} & \multirow[b]{2}{*}{ Total } \\
\hline & & -200 & 0 & 200 & 400 & \\
\hline \multirow[t]{4}{*}{ Controls } & Begin-related & 3 & 4 & 2 & 6 & 15 \\
\hline & Begin Unrelated & 5 & 4 & 6 & 8 & 23 \\
\hline & End-related & 4 & 2 & 6 & 1 & 13 \\
\hline & End Unrelated & 6 & 4 & 4 & 4 & 18 \\
\hline \multirow[t]{4}{*}{ NP } & Begin-related & 8 & 8 & 6 & 7 & 29 \\
\hline & Begin-unrelated & 10 & 16 & 14 & 18 & 58 \\
\hline & End-related & 12 & 15 & 12 & 13 & 52 \\
\hline & End-unrelated & 13 & 12 & 11 & 13 & 49 \\
\hline
\end{tabular}

Turning now to the nature of the errors, of the 69 trials that were failed for the older controls, $82.6 \%$ (57) were substitutions of semantically related words (e.g., "binoculars" instead of goggles), 5.8\% (4) were formal paraphasias (e.g., "mutton" instead of button) and $11.6 \%$ (8) were caused by other errors or failures to respond. For $\mathrm{NP}$, of the total 188 trials that were failed (incorrectly named or not attempted, $36.7 \%$ 
(69) were substitutions of semantically related words (e.g., "chocolate" instead of biscuits; "bird" instead of parrot), $4.3 \%$ (8) were formal paraphasias and 59.0\% (111) were caused by other errors or failures to respond. Appendix D shows a detailed report of the different types of outright naming errors made across the different distractor and SOA conditions for the control participants and NP.

\section{Naming Latency Analysis}

Prior to analysis of latency data, the following pruning procedures were applied (as in phase one). First, latencies where participants produced three or more fails on the target across all their sessions were removed. This resulted in a loss of $0.38 \%$ of the data for the older controls and $2.3 \%$ for NP. Second, outliers, defined as responses that were 2.5 standard deviations above the mean, were also removed resulting in a further loss of $2.71 \%$ of trials for the control group and $2.6 \%$ for NP. Upon analysis of the raw data, an excessively positive skew was observed for both groups (control group skew value: 1.98; NP skew value: 2.51 ). Therefore, the naming latency data were log transformed prior to analysis producing a new skew value of 0.97 for the controls and 1.25 for NP (1.25 is still a very positive skew but closer to the top limit of 1 for a relatively normal distribution; and adequate for an ANOVA analysis to produce meaningful data). Table 3.5 shows the geometric mean naming latencies to correct responses for the older controls across SOAs and distractor conditions. 
Table 3.5.

Geometric mean naming latencies of correct responses across the four distractor conditions and SOAs for the older controls and NP (figures in brackets are the values that lie one standard deviation below and above the mean respectively).

\begin{tabular}{|c|c|c|c|c|c|}
\hline \multirow[b]{2}{*}{ Participant } & \multirow[b]{2}{*}{ Condition } & \multicolumn{4}{|c|}{ Target SOA } \\
\hline & & $-200 \mathrm{~ms}$ & $0 \mathrm{~ms}$ & $+200 \mathrm{~ms}$ & $+400 \mathrm{~ms}$ \\
\hline \multirow[t]{4}{*}{ Controls } & Begin-related & $806(649,937)$ & $790(607,939)$ & $791(612,937)$ & $809(656,938)$ \\
\hline & Begin unrelated & $831(664,970)$ & $867(653,1038)$ & $848(641,1014)$ & $820(642,966)$ \\
\hline & End-related & $798(628,938)$ & $817(641,962)$ & $821(647,964)$ & $846(665,995)$ \\
\hline & End unrelated & $796(635,930)$ & $819(659,953)$ & $832(657,976)$ & $845(644,1007)$ \\
\hline \multirow[t]{4}{*}{ NP } & Begin-related & $1565(773,3171)$ & $1478(788,2771)$ & $1621(843,3115)$ & $1690(957,2982)$ \\
\hline & Begin unrelated & $1835(851,3957)$ & $1661(883,3125)$ & $1904(951,3815)$ & $1995(1045,3807)$ \\
\hline & End-related & $1784(813,3914)$ & $1527(782,2982)$ & $1534(778,3023)$ & $1428(868,2348)$ \\
\hline & End unrelated & $1426(777,2616)$ & $1847(862,3959)$ & $1712(845,3470)$ & $1741(924,3281)$ \\
\hline
\end{tabular}


A brief overview of Table 3.5 suggests that the begin-related distractors appear to have a facilitatory effect at all SOAs compared to corresponding unrelated distractors for both NP and the older controls. End-related distractors appear to have very little or negligible difference in reaction times compared to corresponding unrelated distractors for the control participants. However, the facilitation effect of end-related distractors appears larger for NP especially at later SOAs.

Figure 3.1 show the percentage difference in latency between each phonologically related condition and its respective control across the four SOAs for NP and the controls. A brief inspection of the figure suggests that the begin-related conditions generally elicited faster latencies than their unrelated controls at all presentation times. For the older control participants, the end-related conditions produced faster latencies than their unrelated controls only at $0 \mathrm{~ms}$ and $200 \mathrm{~ms}$. At $-200 \mathrm{~ms}$ and $400 \mathrm{~ms}$, the relative control condition produced faster latencies compared to the end-related condition. The most marked differences between begin and end conditions can be observed at the SOAs of 200ms, 0ms and 200ms. For NP, the end-related condition produced faster latencies than their unrelated controls at $0 \mathrm{~ms}, 200 \mathrm{~ms}$ and $400 \mathrm{~ms}$. A strong inhibitory effect can be observed at $-200 \mathrm{~ms}$ for the end effect where unrelated distractors produced faster latencies compared to end-related distractors. The most marked differences between begin and end conditions can be observed at the SOAs of -200ms and 0ms. 


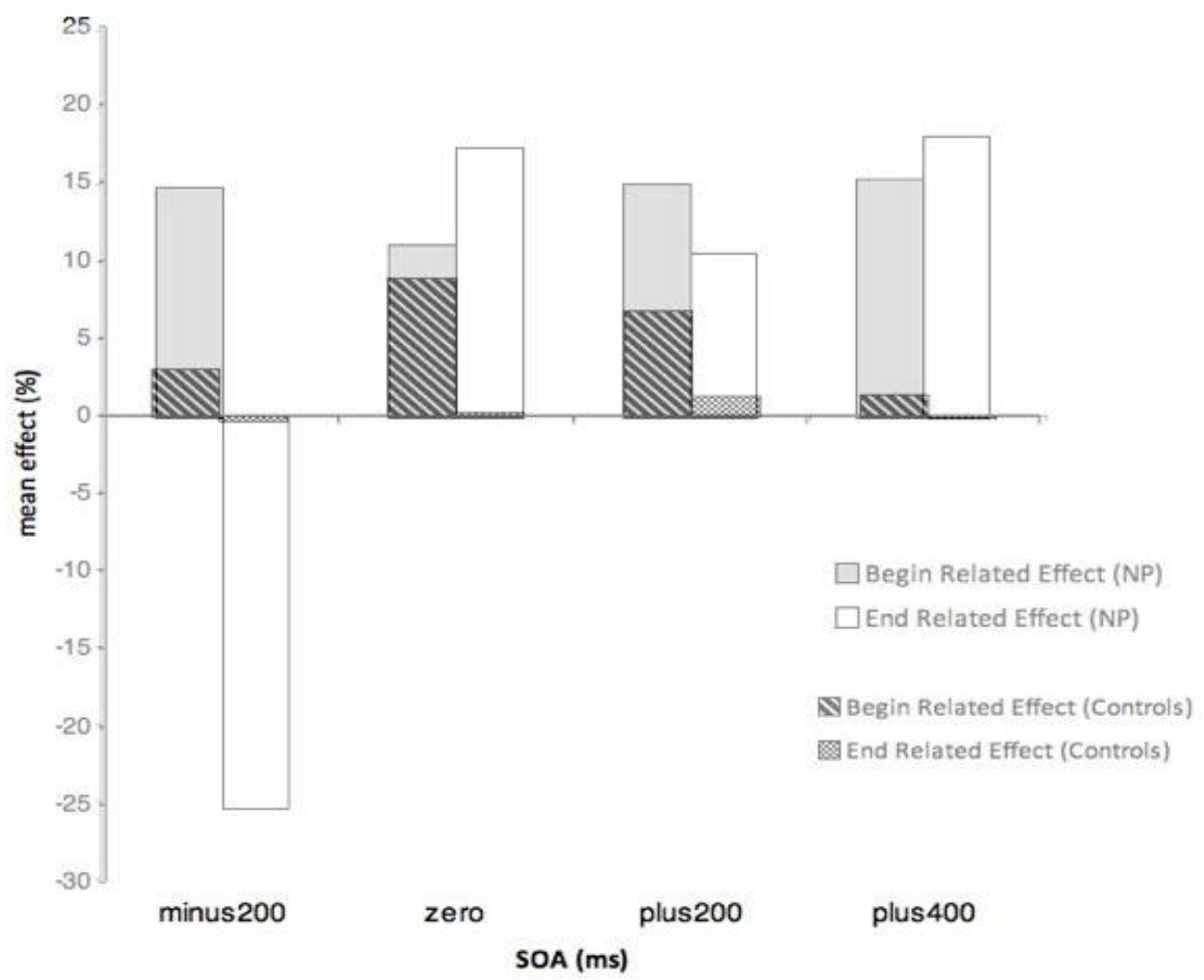

Figure 3.1. The percentage difference in latency between each phonologically related condition and its respective unrelated control across the four SOAs for NP and the older controls are displayed. These values were obtained by first subtracting the geometric mean latency of the phonologically related condition (begin-related or end-related) from its respective unrelated control, then expressing this difference as a percentage of the latter value. 
The naming latencies for the older controls and NP were initially analysed independently. For the older controls, a general linear mixed model analysis of the latency data incorporating both participants and target name as random effects revealed a significant main effect of distractor type, $F(3,8745)=39.21, p<0.0001$, and of SOA, $F(1,8745)=45.39, p<0.0001$, and a significant distractor type by SOA interaction, $\mathrm{F}(3,8745)=17.57, p<0.0001)$. Planned comparisons revealed a significant main effect of begin-relatedness (begin-related vs. begin-unrelated), $F(1,8745)=110.76, p<0.0001$. Pairwise comparisons revealed a significant begin relatedness effect (begin-related vs. begin-unrelated) at all four SOAs ( $p<0.0001$ at all four onsets). However, there was no significant effect of end-relatedness at $-200 \mathrm{~ms}(p=0.42), 0 \mathrm{~ms}(p=0.11)$ and 400ms $(p=0.13)$, with marginal significance at the onset of $200 \mathrm{~ms}(p=0.05)$. This effect did not interact significantly with SOA, $F(1,8745)=3.10, p=0.08$. There was no significant main effect of end-relatedness (End-related vs. End-unrelated), $F(1,8745)=2.52, p=0.11$, and no significant interaction between this effect and SOA, $F(1,8745)=0.20, p=0.66$.

For NP, a general linear mixed model analysis of the latency data across items revealed a significant main effect of distractor type, $F(3,1097)=2.90, p<0.05$, but not for SOA, $F(1,1097)=0.85, p=0.36$. There was a significant distractor type by SOA interaction, $F(3,1097)=2.74, p<0.05$. Planned comparisons revealed a significant main effect of begin-relatedness (begin-related vs. begin-unrelated), $F(1,1097)=8.32, p<0.01$. However, this effect did not interact significantly with $\operatorname{SOA}, F(1,1097)=0.04, p=0.85$. There was no significant main effect of end-relatedness (end-related vs. end-unrelated), $F(1,1097)=0.0, p=0.99$ but a significant interaction between this effect and SOA, $F(1,1097)=6.08, p<0.05$. Pairwise comparisons revealed a significant begin relatedness 
effect (begin-related vs. begin-unrelated) at $0 \mathrm{~ms}(p<0.01), 200 \mathrm{~ms}(p<0.01)$ and $400 \mathrm{~ms}$ $(p<0.05)$ but not at $-200 \mathrm{~ms}(p=0.07)$. There was no significant end-relatedness effect at the early onsets of $-200 \mathrm{~ms}(p=0.19)$ and $0 \mathrm{~ms}(p=0.99)$. There was a significant effect however at the later onsets of 200ms $(p<0.05)$ and 400ms $(p<0.01)$.

A combined analysis of the log transformed data from both the older controls and NP was also carried out. Here, the participant group (NP versus older controls) was included as an independent variable (fixed effect), and both participant and target name were included as random. In this analysis, there was an overall main effect of participant group, $F(1,9905)=52.98, p<0.0001$, which indicates that NP was generally slower at naming the target items compared to the older controls. There was also a significant interaction between participant group and distractor condition, $F(3,9905)=11.46$, $p<0.0001$ which support the conclusion that there was a stronger effect of distractor condition on NP's naming latencies than on those of the older controls.

\section{Discussion}

The older controls and NP produced an interesting set of findings in their performances on the task. The older controls produced an almost identical pattern of facilitation for begin-related distractors to the younger controls: distractors significantly facilitated target picture naming compared to the corresponding unrelated distractors at all four distractors onsets (SOAs). Also the differences in facilitatory effects for the older controls across the four SOAs reached significance suggesting that facilitatory effects were dependent on SOA just as they were for the young controls. This pattern of facilitation is consistent with previous studies that investigated phonological facilitation effects on a similar age group (e.g. Taylor \& Burke, 2002; see Wilshire et al., 2007 who 
failed to find an effect). This finding supports the idea that phonologically related words potentially strengthen weak connections between lexical and phonological units resulting in reduced naming latencies. The end-related distractors however did not produce significant phonological facilitation effects at $-200 \mathrm{~ms}$, $0 \mathrm{~ms}$ and $400 \mathrm{~ms}$ SOAs, with marginal significance at 200ms. Also, end-related phonological facilitation effects did not vary significantly across the SOAs suggesting that the positioning of distractors did not affect naming latencies. This finding supports our hypothesis as previous researchers (e.g. Taylor \& Burke, 2002; Burke \& Shafto, 2004) found naming performance to be improved only upon presentation of a distractor that shared initial phonemes to the target. Though none of these studies have used an end-related distractor, we can only assume that the poor facilitation effects were due to the weakening in network connections between lexical and phonological representations. Unlike the significant differences between the distractor types produced for the younger controls, there is little evidence from the older controls to suggest a serial pattern of phoneme retrieval during phonological encoding. The distractor onset of $400 \mathrm{~ms}$ did not produce significant effects for end-related distractors, but there is marginal significance at $200 \mathrm{~ms}$, similar to the younger controls. So perhaps we could assume that there is serial retrieval of phonemes happening here but the task was not able to capture this effect clearly. Also we only recruited a small number of older controls which may have contributed to a lower power in the results.

NP, however, as expected produced exaggerated effects for both begin and end distractor conditions across the four SOAs, though not all of these were significant. These exaggerated effects may be attributed to NP's abnormally slow word production 
processes compared to normal functioning individuals (Wilshire \& Saffran, 2005;

Wilshire et al., 2007). NP's ability to process related and unrelated phonological (beginrelated) distractors were also investigated by Wilshire et al. (2007), and this appeared to be normal, so the distractors cannot completely account for the exaggerated facilitation effects produced. The begin-related distractors produced significant facilitation effects from the time of target presentation $(0 \mathrm{~ms})$ as well as at $200 \mathrm{~ms}$ and at $400 \mathrm{~ms}$ but not at the earliest onset of $-200 \mathrm{~ms}$. They did not however produce significantly varying facilitation effects across the different SOAs suggesting that SOA had little or no effect on NP's naming. The end-related distractors produced significant facilitation effects at later SOAs $200 \mathrm{~ms}$ and $400 \mathrm{~ms}$ but not at the early SOAs of $-200 \mathrm{~ms}$ and $0 \mathrm{~ms}$. Instead, at $200 \mathrm{~ms}$, a rather strong inhibitory effect is observed (the significance of this effect was not investigated as it was not directly relevant to the study). This is where NP's naming latency would have been slowed due to the presence of an end-related distractor. There is very limited literature on picture-word interference tasks on aphasic speakers so it is unknown why this inhibitory effect was observed. According to the two-step interactive activation model, a possible explanation could be that the end-related distractors activated other lexical representations through feedback activation from the phonological level. Due to NP's lexical impairment, abnormally strong competition in selecting between the distractor and target may have resulted in slower naming latencies.

The facilitation patterns produced by the begin-related and end-related distractors on NP's naming latencies provide strong evidence for serial retrieval of phonemes during phonological encoding. This finding is supported by the two-stage model discussed previously where begin-related distractors and end-related distractors are thought to exert 
their effects at different stages of word production (Meyer \& Schriefers, 1991; Wilshire \& Saffran, 2005). The begin-related distractors produced strong facilitatory effects at early SOAs and diminished effects at later SOAs which suggest that encoding of initial phonemes of the target were happening first. The end-related distractors produced strong facilitatory effects at later SOAs and strong inhibitory effects at early SOAs which suggest that the end phonemes of the target were encoded at a later time after target presentation.

Another interesting observation is that in contrast to the control groups, beginrelated distractors did not produce significant facilitatory effects at -200ms SOA for NP. This finding could be attributed to the lexical competition between target and distractor. Alternatively, though NP's ability to process the relatedness of the phonological distractors was relatively normal, the time taken to process the distractor may have been slower than normal. The extent to which distractor processing speed offsets word production is still not clear. To account for generally slower processing speeds, a late SOA of 400ms was used in this study. However, NP was very slow which poses the question - was extending out to 400ms far enough? A future option could investigate performance on the task by extending out to other SOAs (i.e. $500 \mathrm{~ms}, 600 \mathrm{~ms}$, etc).

Facilitation effects of begin-related distractors at 400ms appeared significantly larger for NP compared to the two control groups. Two things might be abnormal in NP: First, he might be abnormally slow. So that might explain why the facilitation effects are more flat across the SOAs (a greater spread of lexical access times). Second, NP seems to have a selective impairment in lexical selection. So the abnormalities he shows in the task 
Word Form Retrieval in Spoken Word Production

might support the feedback view - that begin related distractors feed activation back to the lexical level, therefore facilitating lexical selection. 


\section{CHAPTER FOUR}

\section{CONCLUSION}

\section{Purpose and findings of the study}

The aim of this study was to investigate the manner in which phonemes are retrieved during the phonological encoding stage of word production.

First, two of the most influential models of word production with developed phonological components were introduced. These two models posed different ideas on the process of phoneme retrieval. The two-step interactive activation model (Dell \& O’Seaghda, 1991; 1992; Dell et al., 1997; Foygel \& Dell, 200) suggested parallel activation but serial retrieval of phonemes whereas the WEAVER model (Roelofs, 1997; Roelofs, 2004) suggested parallel activation and retrieval of phonemes followed by a serial pattern of syllabification. Due to this major difference between the models, we decided to investigate the issue of phoneme retrieval using the auditory picture-word interference task. This task enables us to track the time course of phonological encoding during word production by observing facilitation effects produced by phonological distractors.

There is only a handful of literature that investigates the phoneme ordering process and these studies have been mainly conducted in Dutch using monosyllabic targets and distractors. Normal word production processes are relatively quick so any facilitation effects produced especially by end-related distractors may have been too small to be captured. We extended our task to an older group of participants, used bisyllabic words and increased the length between distractor onsets and target presentation (SOAs) so that we could investigate an aphasic individual, NP. 
Our findings from this study support a serial pattern of phoneme retrieval. For all participant groups, significant phonological facilitation effects of begin-related distractors were observed at early SOAs. This suggests that initial phonemes of the target word were encoded at an early stage. Significant phonological facilitation effects for endrelated distractors were observed at later SOAs for both the young control group and NP. The older controls only produced marginal significance at $200 \mathrm{~ms}$ after target presentation. These findings suggest that later or end phonemes of a word are encoded after initial phonemes.

Our findings also support a theory of lexical access posed by the two-step interactive activation model as facilitatory effects especially for begin-related distractors were observed at relatively early onsets. It could be alternatively argued that the facilitation effects produced were actually happening at the phonological stage of encoding. We used bisyllabic targets and distractors; therefore what is thought to be the serial retrieval of phonemes could actually have been the serial process of syllabification posed by the WEAVER model. A problem with this assumption is that syllabification occurs at a very late stage of phonological encoding. So, if distractors were to exert their effects at the phonological stage of word production, late facilitation effects would have been observed at 400ms for both control groups (Wilshire et al., 2007).

The older control group produced significantly slower naming latencies compared to the young controls. Studies on aging and performance on naming tasks have suggested that effects like TOT from weakened lexical and phonological representations would result in slower naming latencies (Taylor \& Burke, 2002; Burke \& Shafto, 2004). However, their slower latencies could have been attributed to some sort of speed- 
accuracy trade off. The younger controls, although significantly faster in their naming latencies, produced a large numbers of naming errors (see APPENDIX C). The older control group on the other hand, were more 'cautious' with their responses from observation during testing. They tried to avoid making mistakes and as a result, their naming speeds slowed down and they produced a small amount of errors as a group.

Another concern was that participants may have developed a strategy to make the task easier by waiting for the distractor to play first before naming the target. This concern has arisen in several studies (e.g. Meyer \& Schriefers, 1991; Starreveld, 2000). If participant did adapt this strategy for naming, we would have expected to see a positive linear relationship between naming latencies with increasing SOA. Fortunately, this was not the case and similar to previous findings (e.g. Schriefers et al., 1990; Meyer \& Schriefers, 1991; Wilshire et al., 2007) naming latencies reduced at later SOAs.

An additional observation is that NP showed similar patterns of phonological facilitation for begin-related distractors as originally observed in 2005, which suggests that his word production abilities have neither improved nor worsened since then.

\section{Summary}

The auditory picture-word interference task is an important investigative tool in word production analyses. This task can be manipulated to allow the time course of specific word production processes to be analysed. The time course of phonological facilitation effects of begin-related and end-related distractors has provided us with evidence for a serial pattern of phoneme retrieval during the phonological encoding stage. Furthermore, the phonological facilitation effects produced in this study have provided 
evidence towards an interactive model of word production. As word production is a fairly rapid and automatic process in normal individuals, the phoneme ordering process may have been too small to observe. By analysing an aphasic individual who produces exaggerated facilitation effects and abnormally slow naming latencies has given us clearer insight into the phoneme order process. Research on phonological facilitation effects and other processes at the phonological level of word production models is still limited. Aphasic populations could be considered as a major under-utilised resource.

\section{Implications of the current study and future directions}

The current study had addressed several issues posed by its predecessors (Schriefers et al., 1990; Meyer \& Schriefers, 1991; Wilshire et al., 2007). However, there are still some potential issues with the current study. First, the control groups were tested at least three days apart. Previous studies had tested individuals over sessions spaced at least a week apart. The participants may have developed some memory for the items. It is a small concern as there were four versions of the task so no one individual repeated the same order of target presentation twice. There was also a small number of older controls used which may not have produced significance in our data.

So far, this task has been investigated with one aphasic case, NP. However, would we find a similar pattern of phoneme ordering in other aphasic speakers with similar lexical access impairment? Perhaps this task could be extended to incorporate a number of aphasic individuals (though difference in the locus of impairment could prove to be a problem). Or alternatively, we could investigate differences in the phoneme ordering process depending on the locus of impairment amongst aphasic individuals. 
Another concern was the speed-accuracy issue posed by the older controls. If this task were to be replicated, it would be ideal to have control over the amount of time participants had to name the item as opposed to giving them the opportunity to control the rate at which they named the targets. This forces them to make a quick response rather than worry about their accuracy scores which may produce different facilitation effects to the current study. It would also be ideal to run an analysis on the dataset from the older controls using something similar to the EZ-diffusion model (Wagenmakers, van der Maas \& Grasman, 2007) to observe drift rates so that we can ascertain whether slower naming speeds were attributed to slower cognitive functioning from aging or the need to produce accurate responses during the task.

Additionally, it may be useful to extend the task beyond two syllables to investigate the phoneme ordering process. This would allow us to look at facilitation effects of mid segments of words. If serial retrieval of phonemes is supported, we would see early facilitation effects for the first syllable, followed by mid to late effects for the mid syllable and late facilitation effects for the end syllable. 


\section{REFERENCES}

Abel, S., Dressel, K., Bitzer, R., Kümmerer, D., Mader, I., Weiller, C. \& Huber, W (2009). The separation of processing stages in a lexical interference fMRI-paradigm. NeuroImage 44(3), 1113-1124.

Ayora, P., Peressotti, F, Alario, F. X., Mulatti, C., Pluchino, P., Job, R. \& Dell'Acqua, R. (in press). What phonological facilitation tells about semantic interference: a dual-task study.

Baayen, R. H., Davidson, D. J. \& Bates, D. M. (2008). Mixed-effects modelling with crossed random effects for subjects and items. Journal of Memory and Language 59(4), $390-412$.

Benson, D. R., Sheremata, W. A., Bouchard, R., Segarra, J. M., Price, D. \& Geschwind, N. (1973). Conduction aphasia: A clinicopathological study. Archives of Neurology 28, 339-346.

Berg, T. \& Schade, U. (1992). The role of inhibition in a spreading-activation model of language production: I. The psycholinguistic perspective. Journal of Psycholinguistic Research 21(6), 405-434. 
Bloem, I., van den Boogaard, S. \& La Heij, W. (2004). Semantic facilitation and semantic interference in language production: Further evidence for the conceptual selection model of lexical access. Journal of Memory and Language 51, 307-323.

Burke, D. M. \& Shafto, M. A. (2004). Aging and language production. Current Directions in Psychological Science 13(1), 21-24.

Caplan, D., Vanier, M. \& Baker, C. (1986). A case study of reproduction conduction aphasia: I. Word Production. Cognitive Neuropsychology 3(1), 99-128.

Carreiras, M. \& Perea, M. (2002). Masked priming effects with syllabic neighbours in a lexical decision task. Journal of Experimental Psychology: Human Perception and Performance 28(5), 1228-1242.

Cohen, J. D., MacWhinney, B., Flatt, M. \& Provost, J (1993). PsyScope: An interactive graphics system for designing and controlling experiments in the psychology laboratory using Macintosh computers. Behavior Research Methods, Instruments \& Computers 25(2), 257-271.

Costa, A., Alario, F. \& Caramazza, A. (2005). On the categorical nature of the semantic interference effect in the picture-word interference paradigm. Psychonomic Bulletin \& Review 12, 125-131. 
Cruice, L.E., Worrall C. \& Hickson, L. M. H. (2000). Boston naming test results for healthy older Australians: A longitudinal and cross-sectional study. Aphasiology 14(2), $143-155$.

Cutting, J.C. \& Ferreira, V. S. (1999). Semantic and phonological information flow in the production lexicon. Journal of Experimental Psychology: Learning, Memory, and Cognition 25(2), 318-344.

Damian, M. (in press) articulatory duration in single word speech production. Journal of Experimental Psychology: Learning, Memory and Cognition.

Damian, M. F. \& Bowers, J. S. (2009). Assessing the role of orthography in speech perception and production: Evidence from picture-word interference tasks. European Journal of Cognitive Psychology 21(4), 581-598.

Damian, M. F. \& Martin R.C. (1999). Semantic and phonological codes interact in single word production. Journal of Experimental Psychology: Learning, Memory, and Cognition 25, 345-361.

Dell, G. S. (1986). A spreading activation theory of retrieval in sentence production. Psychological Review 93, 283-321. 
Dell, G. S. (1988). The retrieval of phonological forms in production: Test of predictions from a connectionist model. Journal of Memory and Language 27, 124-142.

Dell, G. S. \& O’Seaghdha, P. G. (1991). Mediated and convergent lexical priming in language production: A comment on Levelt et al. (1991). Psychological Review 98, 604614.

Dell, G. S. \& O’Seaghdha, P .G. (1992). Stages of lexical access in language production. Cognition 42, 287-314.

Dell, G. S., Schwartz, M. F., Martin, N., Saffran, E. M. \& Gagnon, D. A. (1997). Lexical access in aphasic and nonaphasic speakers. Psychological Review 104, 801-838.

Diggle, P. (1988). An approach to the analysis of repeated measurements. Biometrics 44, 959-971.

Dunn, L. M., \& Dunn, L. M. (1987). Peabody picture vocabulary test-Third Edition (PPVT-III).

Foygel, D. \& Dell, G.S. (2000). Models of impaired lexical access in speech production. Journal of Memory and Language 43, 182-216. 
Garrett, M. F. (1975). The analysis of sentence production. In G. H. Bower (ed) The Psychology of learning and motivation 9: Advances in Research and Theory (pp. 133177). New York: Academic Press.

Goodglass, H. \& Kaplan, E. (1983). The assessment of aphasia and related disorders (2nd ed.). Philadelphia: Lea \& Feibiger.

Gracco, V. L., Tremblay, P. \& Pike B. (2005). Imaging speech production using fMRI. Neuroimage 15, 26(1), 294-301.

Guenther, F. H., Hampson, M. \& Johnson, D. (1998). A theoretical investigation of reference frames for the planning of speech movements. Psychological Review 105(4), 611-633.

Harley, T. A. (1993). Connectionist approaches to language disorders. Aphasiology 7(3), 221-249.

Hartley, T. \& Houghton, G. (1996). A linguistically constrained model of short-term memory for nonwords. Journal of Memory and Language 35(1), 1-31.

Hashimoto, N. \& Thompson, C. K. (2010). The use of the picture-word interference paradigm to examine naming abilities in aphasic individuals. Aphasiology 24(5), 580611. 
Howard, D., \& Patterson, K. (1992). The pyramids and palm trees test: A test of semantic access from words and pictures. England: Thames Valley Test Company.

Hickok, G. \& Poeppel, D. (2004). Dorsal and ventral streams: A framework for understanding aspects of the functional anatomy of language. Cognition 92(1-2), 67-99.

James, L. E. \& Burke, D .M. (2000). Phonological priming effects on word retrieval and tip-of-the-tongue experiences in young and older adults. Journal of Experimental Psychology: Learning, Memory and Cognition 26, 1378-1391.

Jescheniak, J. D. \& Schriefers, H. (1998). Discrete serial versus cascaded processing in lexical access in speech production: Further evidence from the coactivation of nearsynonyms. Journal of Experimental Psychology: Learning, Memory, and Cognition 24(5), 1256-1274.

Jescheniak, J. D. \& Schriefers, H. (2001). Priming effects from phonologically related distractors in picture-word interference. The Quarterly Journal of Experimental Psychology 54A(2), 371-382.

Kay, J., Lesser, R. \& Coltheart, M. (1992). Psycholinguistic assessments of language processing in aphasia. Hove, UK: LEA. 
Kent, R. D., Adams, S. G. \& Turner, G. S. (1996). Models of speech production. In N. J. Lass (Ed), Principles of Experimental Phonetics. (pp. 3-45). St Louis, Missouri: Mosby.

Kuipers, J., La Heij, W. \& Costa, A. (2006). A further look at semantic context effects in language production: The role of response congruency. Language and Cognitive Processes 21(7-8), 892-919.

Levelt, W.J. M. (1999). Models of word production. Trends in Cognitive Sciences 3(6), 223-232.

Levelt, W. J. M., Roelofs, A. \& Meyer A. S. (1999). A theory of lexical access in speech production. Behavioral and Brain Sciences 22, 1-75.

Martin, N., Gagnon, D. A., Schwartz, M.F., Dell, G. S. \& Saffran, E. M. (1996). Phonological facilitation of semantic errors in normal and aphasic speakers. Language and Cognitive Processes 11(3), 257-282.

Meyer, A. S. (1996). Lexical access in phrase and sentence production: Results from picture-word interference experiments. Journal of Memory and Language 35(4), 477 496. 
Meyer, A. S. \& Belke, E. (2007). Word form retrieval in language production. In G. Gaskell (Ed.), Oxford handbook of psycholinguistics (pp. 471-487). Oxford University Press.

Meyer, A. S. \& van der Meulen, F. F. (2000). Phonological priming effects on speech onset latencies and viewing times in object naming. Psychonomic Bulletin \& Review 7(2), 314-319.

Meyer, A.S., Roelofs, A. \& Levelt, W. J. M. (2003). Word length effects in object naming: The role of a response criterion. Journal of Memory and Language 48(1), 131147.

Meyer, A. S. \& Schriefers, H. (1991). Phonological facilitation in picture-word interference experiments: Effect of stimulus onset asynchrony and types of interfering stimuli. Journal of Experimental Psychology: Learning, Memory and Cognition 17, 1146-1160.

Morsella E. \& Miozzo, M. (2002). Evidence for a cascade model of lexical access in speech production. Journal of Experimental Psychology: Learning, Memory, and Cognition 28(3), 555-563. 
Navarrete, E. \& Costa, A. (2005). Phonological activation of ignored pictures: Further evidence for a cascade model of lexical access. Journal of Memory and Language 53(3), $359-377$.

Ratcliff, R. (1993). Methods for dealing with reaction time outliers. Psychological Bulletin 114(3), 510-532.

Roelofs, A. (1997). The WEAVER model of word-form encoding in speech production. Cognition 64, 249-284.

Roelofs, A. (2004). Seriality of phonological encoding in naming objects and readings their names. Memory \& Cognition 32(2), 212-222.

Saffran, E. M., Schwartz, M. F., Linebarger, M., Martin, N., \& Bochetto, P. (1988). The Philadelphia Comprehension Battery. Unpublished Test.

Schriefers, H., Meyer, A. S. \& Levelt, W. J. M. (1990). Exploring the time course of lexical access in language production: Picture-word interference studies. Journal of Memory and Language 29, 86-102.

Sevald, C. A. \& Dell, G. S. (1994). The sequential cuing effect in speech production. Cognition 53(2), 91-127. 
Shattuck-Hufnagel, S., Keller, E., Gopnik, M. (1987). The role of word-onset consonants in speech production planning: New evidence from speech error patters. In Motor and sensory processes of language. (pp. 17-51). Hillsdale, NJ, England: Lawrence Erlbaum Associates, Inc.

Shattuck-Hufnagel, S. \& Klatt, D. H. (1979). The limited use of distinctive features and markedness in speech production: Evidence from speech error data. Journal of Verbal Learning \& Verbal Behavior 18(1), 41-55.

Starreveld, P. A. (2000). On the interpretation of onsets of auditory context effects in word production. Journal of Memory and Language 42, 497-425.

Starreveld, P. A. \& La Heij, W. (2004). Phonological facilitation of grammatical gender retrieval. Language and Cognitive Processes 19(6), 677-711.

Stemberger, J. P. (1985). An interactive activation model of language production. In A. Ellis (Ed.), Progress in the psychology of language (pp. 143-186). London: Lawrence Erlbaum \& Associates.

Taylor, J. K. \& Burke, D. M. (2002). Asymmetric aging effects on semantic and phonological processes: Naming in the picture-word interference task. Psychology and Aging 17(4), 662-676. 
Ventura, P., Kolinsky, R., Querido, J. L., Fernandes, S. \& Morais, J. (2007). Is phonological encoding in naming influenced by literacy. Journal of Psycholinguistic Research 36(5), 341-360.

Vousden, J. I., Brown, G. D. A. \& Trevor, A. (2000). Serial control of phonology in speech production: A hierarchical model. Cognitive Psychology 41(2),101-175.

Wagenmakers, E. J., van der Mass, H. L. \& Grasman, R. P. (2007). An EZ-diffusion model for response time and accuracy. Psychonometric Bulletin Review 14(1), 3-22.

Wilshire, C. E. (2002). Where do aphasic phonological errors come from? Evidence from phoneme movement errors in picture naming. Aphasiology 16, 169-197.

Wilshire, C. E. \& Fisher C. A. (2003). Phonological dysphasia: A cross-modal phonological impairment affecting repetition, production and comprehension. Cognitive Neuropsychology 21(2-4), 187-210.

Wilshire, C. E \& Saffran, E. M. (2005). Contrasting effects of phonological priming in aphasic word production. Cognition 95(1), 31-71.

Wilshire, C. E., Keall, L. M., Stuart, E. J. \& O’Donnell D. J. (2007). Exploring the dynamics of aphasic word production using the picture-word interference task: A case study. Neuropsychologia 45(5), 939-953. 
Wise, R. J. S., Scott, S. K., Blank, S. C., Mummery, C. J., Murphy, K. \& Warburton, E. A. (2001). Separate neural sub-systems within "Wernicke's area". Brain: A Journal of Neurology 124(1), 83-95.

de Zubicaray, G. I. \& McMahon, K. L. (2009). Auditory context effects in picture naming investigated with event-related fMRI. Cognitive, Affective \& Behavioral Neuroscience 9(3), 260-269.

de Zubicaray, G., McMahon, K, Eastburn, M, Pringle, A J, Lorenz, L. \& Humphreys, M. S. (2006). Support for an auto-associative model of spoken cued recall: Evidence from fMRI. Neuropsychologia 45(4), 824-835. 
APPENDIX A

\section{List of stimulus items}

Target Items (Pictures)

\begin{tabular}{|c|c|c|c|}
\hline Anchor & Angel & Ankle & Apple \\
\hline Apron & Arrow & Baby & Bacon \\
\hline Balloon & Barrel & Biscuits & Bottle \\
\hline Bubbles & Bucket & Bullet & Butter \\
\hline Button & Camel & Camera & Candle \\
\hline Cannon & Carrot & Cherry & Chimney \\
\hline Chocolate & Circle & Coffee & Collar \\
\hline Diamond & Dolphin & Donkey & Dragon \\
\hline Elbow & Fairy & Feather & Finger \\
\hline Fountain & Funnel & Garlic & Goggles \\
\hline Halo & Hammer & Hammock & Helmet \\
\hline Honey & Igloo & Island & Jelly \\
\hline Jockey & Kettle & Kitchen & Label \\
\hline Ladder & Lemon & Letter & Lettuce \\
\hline Lion & Llama & Locket & Magnet \\
\hline Marbles & Medal & Mermaid & Mirror \\
\hline Money & Monkey & Muzzle & Onion \\
\hline Parrot & Peacock & Pencil & Pillow \\
\hline Pirate & Pocket & Pumpkin & Puppet \\
\hline Rabbit & Rainbow & Rattle & Razor \\
\hline
\end{tabular}


Word Form Retrieval in Spoken Word Production

$\begin{array}{llll}\text { Saddle } & \text { Sausage } & \text { Scissors } & \text { Seesaw } \\ \text { Shadow } & \text { Spider } & \text { Table } & \text { Ticket } \\ \text { Tiger } & \text { Tractor } & \text { Trumpet } & \text { Turkey } \\ \text { Wallet } & \text { Whistle } & \text { Window } & \text { Zebra }\end{array}$

Auditory Distractor Items

\begin{tabular}{|c|c|c|c|}
\hline Aintree & Alley & Almond & Ancient \\
\hline Angle & Angry & Annex & Anthem \\
\hline Apex & April & Aqua & Arab \\
\hline Arid & Attic & Bagel & Bailiff \\
\hline Baker & Ballcock & Banner & Baroque \\
\hline Basic & Basil & Basin & Batter \\
\hline Battle & Bazaar & Beagles & Beetle \\
\hline Berry & Billion & Bisto & Bistro \\
\hline Blanket & Body & Bonnet & Borrow \\
\hline Boulder & Boxer & Bracket & Brother \\
\hline Buckle & Buddha & Buddy & Budget \\
\hline Budgie & Buffer & Buggy & Bugles \\
\hline Bully & Bunny & Bureau & Busker \\
\hline Butcher & Buzzer & Cabin & Cables \\
\hline Caddy & Camping & Campus & Cancer \\
\hline Canvas & Carpet & Carriage & Carton \\
\hline Cashew & Cassock & Castle & Catholic \\
\hline Cattle & Cauldron & Cedar & Cellar \\
\hline
\end{tabular}


Word Form Retrieval in Spoken Word Production

\begin{tabular}{|c|c|c|c|}
\hline Cello & Centre & Chalet & Cheddar \\
\hline Chemist & Chicken & Chisel & Chopper \\
\hline Chopsticks & Chutney & City & Claret \\
\hline Cobra & Cockney & Coffin & Coma \\
\hline Comet & Comma & Cookie & Copper \\
\hline Copy & Coral & Cricket & Crossbow \\
\hline Cudgel & Curate & Curlew & Curry \\
\hline Curtain & Cycle & Dagger & Debit \\
\hline Diary & Diesel & Diet & Dolby \\
\hline Doldrums & Donald & Dongle & Drabble \\
\hline Drastic & Dribbles & Elder & Elfin \\
\hline England & Era & Error & Eyelid \\
\hline Fables & Fairground & Falcon & Fellow \\
\hline Ferret & Ferry & Figure & Fillet \\
\hline Filter & Finish & Firkin & Flora \\
\hline Formal & Fossil & Founder & Foundry \\
\hline Freezer & Furrow & Fussy & Gable \\
\hline Gamble & Garden & Garland & Garter \\
\hline German & Gesture & Gherkin & Glider \\
\hline Glitter & Goddess & Gossip & Granny \\
\hline Gullet & Habit & Hacksaw & Haddock \\
\hline Haggis & Happy & Hanky & Hatred \\
\hline
\end{tabular}


Word Form Retrieval in Spoken Word Production

\begin{tabular}{|c|c|c|c|}
\hline Haven & Healthy & Helper & Hobby \\
\hline Hockey & Horror & Huddle & Hurry \\
\hline Husky & Hustle & Icon & Idol \\
\hline Ignite & Ignore & Jacket & Jargon \\
\hline Jester & Jesus & Jiffy & Jigsaw \\
\hline Jogger & Jotter & Journal & Journey \\
\hline Judo & Jumbo & Junket & Junkie \\
\hline Justice & Kennel & Ketchup & Kidney \\
\hline Kilo & Kipper & Kitten & Lackey \\
\hline Ladle & Lady & Laser & Latin \\
\hline Latte & Lattice & Laughing & Leather \\
\hline Ledger & Legend & Lemming & Leopard \\
\hline Lesson & Libra & Lighter & Limbo \\
\hline Linen & Lolly & Lorry & Lozenge \\
\hline Ludo & Luncheon & Lychee & Magma \\
\hline Magpie & Mallet & Maple & Margin \\
\hline Market & Matron & Meadow & Menu \\
\hline Mercy & Merit & Message & Metal \\
\hline Meter & Middle & Mini & Miser \\
\hline Mitten & Monday & Mongrel & Mother \\
\hline Muddle & Muffin & Mugger & Murder \\
\hline Muscle & Musket & Mutton & Needle \\
\hline Nettle & Notice & Oboe & Otter \\
\hline
\end{tabular}


Word Form Retrieval in Spoken Word Production

\begin{tabular}{|c|c|c|c|}
\hline Oven & Over & Package & Packet \\
\hline Pagan & Palace & Palette & Passage \\
\hline Pattern & Peanut & Pebble & Pellet \\
\hline Pendant & Penny & Pension & Petal \\
\hline Pharaoh & Pickle & Pigeon & Pillar \\
\hline Pinky & Piper & Pity & Pizza \\
\hline Planet & Platter & Poker & Poodle \\
\hline Poppy & Possum & Public & Puffin \\
\hline Pumice & Pummel & Putty & Puzzle \\
\hline Pylon & Quarrel & Racquet & Radish \\
\hline Rally & Ranger & Ration & Raven \\
\hline Raymond & Rayon & Rebels & Reindeer \\
\hline Remade & Riddle & Rocket & Ruby \\
\hline Saffron & Salmon & Saloon & Seagull \\
\hline Secret & Sequin & Sermon & Servant \\
\hline Shackles & Shannon & Sherbet & Shuttle \\
\hline Silo & Snippet & Socket & Sonnet \\
\hline Sparkle & Spicy & Spiral & Spirit \\
\hline Stallion & Steeple & Stomach & Stopcock \\
\hline Strumpet & Stubble & Sugar & Summer \\
\hline Summit & Surgeon & Surplus & Syrup \\
\hline Tablet & Tailor & Taker & Tassel \\
\hline Thermal & Thicket & Thistle & Thunder \\
\hline
\end{tabular}


Word Form Retrieval in Spoken Word Production

$\begin{array}{llll}\text { Tiller } & \text { Tissue } & \text { Token } & \text { Tracksuit } \\ \text { Traction } & \text { Trainee } & \text { Trauma } & \text { Trigger } \\ \text { Trophy } & \text { Trouble } & \text { Trousers } & \text { Truffle } \\ \text { Truncheon } & \text { Tumour } & \text { Turban } & \text { Turnip } \\ \text { Turret } & \text { Typhoon } & \text { Typist } & \text { Tyrant } \\ \text { Uncle } & \text { Undies } & \text { Unmade } & \text { Vigil } \\ \text { Violet } & \text { Warren } & \text { Washer } & \text { Whippet } \\ \text { Whisker } & \text { Whiskey } & \text { Whisper } & \text { Widow } \\ \text { Willow } & \text { Windsor } & \text { Winter } & \text { Wrapper } \\ \text { Wrestle } & \text { Yellow } & \text { Zenith } & \text { Zephyr } \\ \text { Zulu } & & & \end{array}$

\section{Samples of stimulus pictures used}

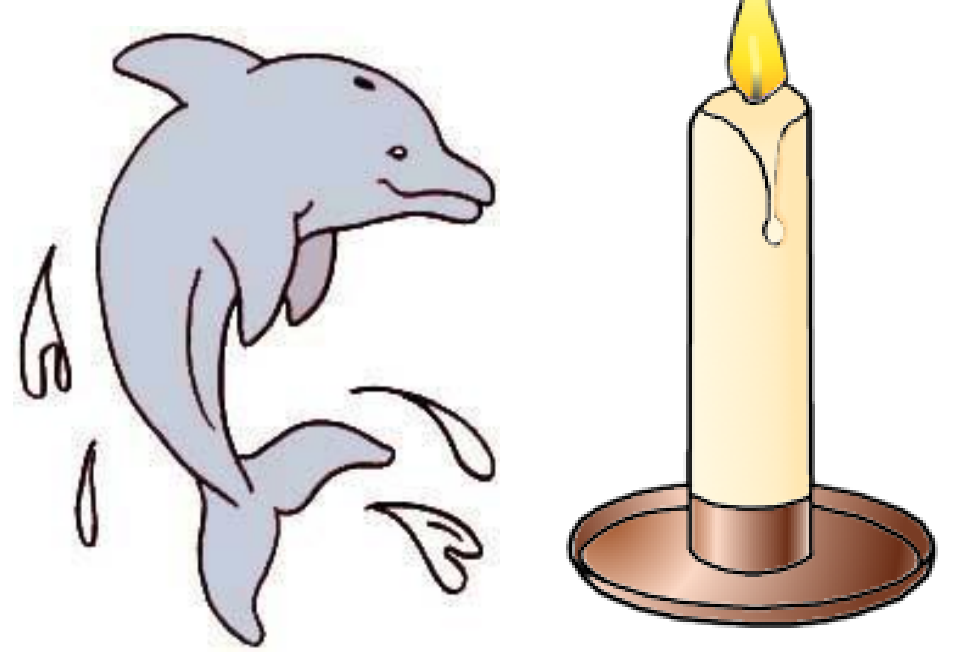



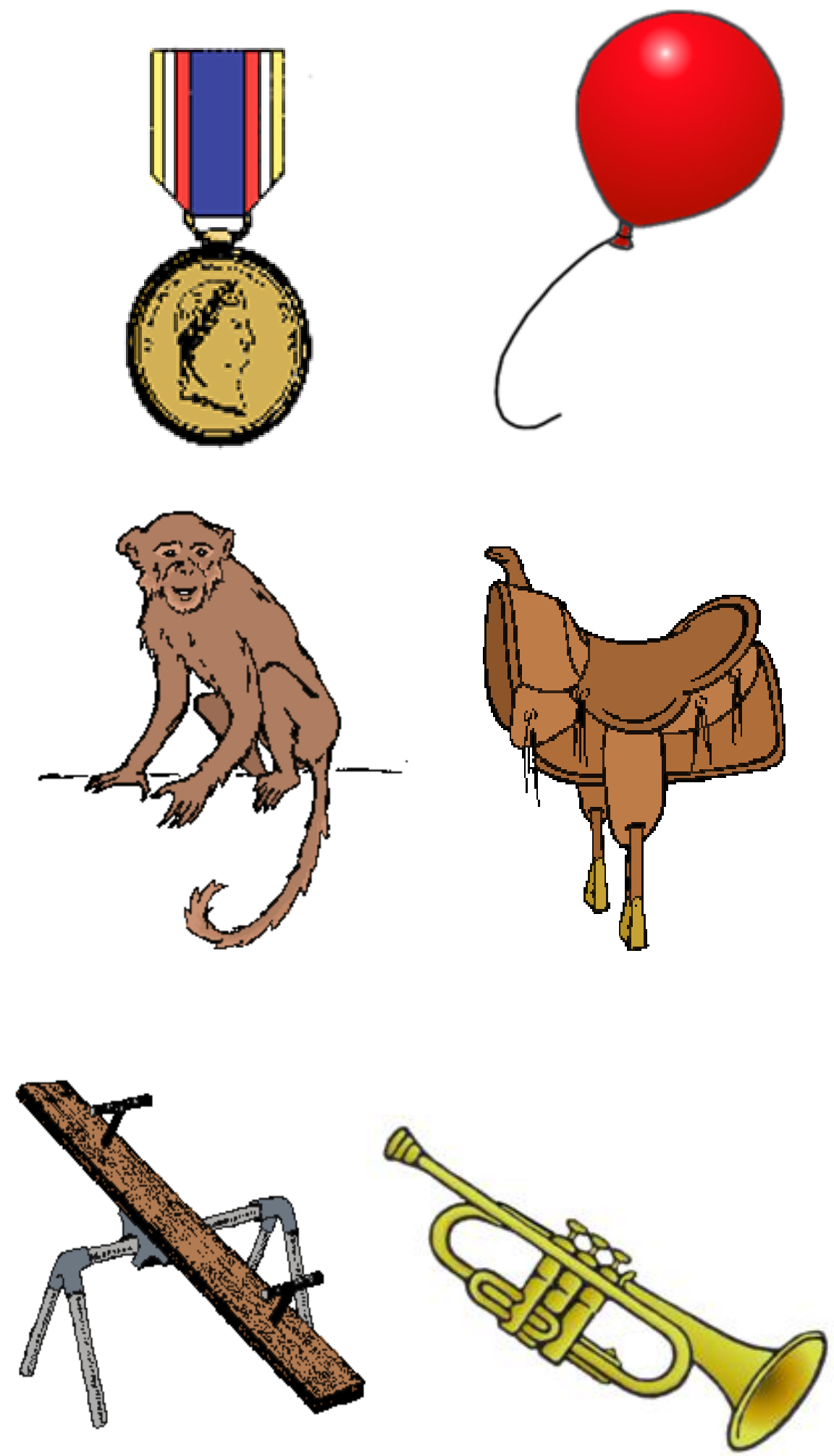
APPENDIX B

\section{Experiment Questionnaire}

Age:

$\begin{array}{llll}\text { Native Speaker of English: } & \mathrm{Y} & / & \mathrm{N}\end{array}$ (please circle)

Normal/Corrected Hearing: $\mathrm{Y}$ / N

Normal/Corrected Vision: $\mathrm{Y}$ / $\mathrm{N}$

Any history of brain trauma/injury: $\quad$ Y / N

If yes please specify:

Handedness: Right handed / Left handed (please circle) 
Word Form Retrieval in Spoken Word Production

\section{APPENDIX C}

A tally report of the types of outright naming errors and omissions made across the different distractor and SOA conditions for the young controls

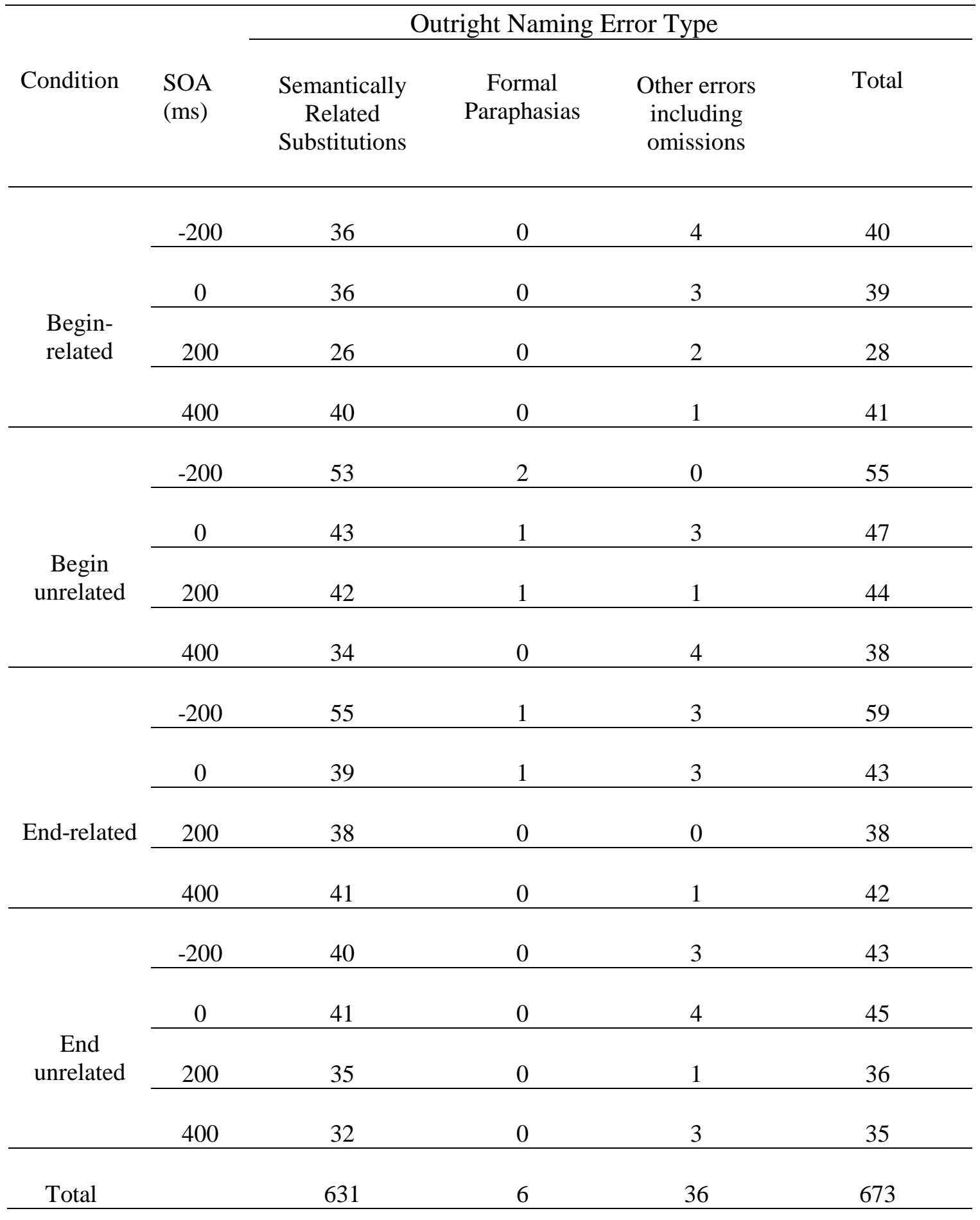


Word Form Retrieval in Spoken Word Production

\section{APPENDIX D}

A tally report of the types of outright naming errors and omissions made across the different distractor and SOA conditions for the older controls

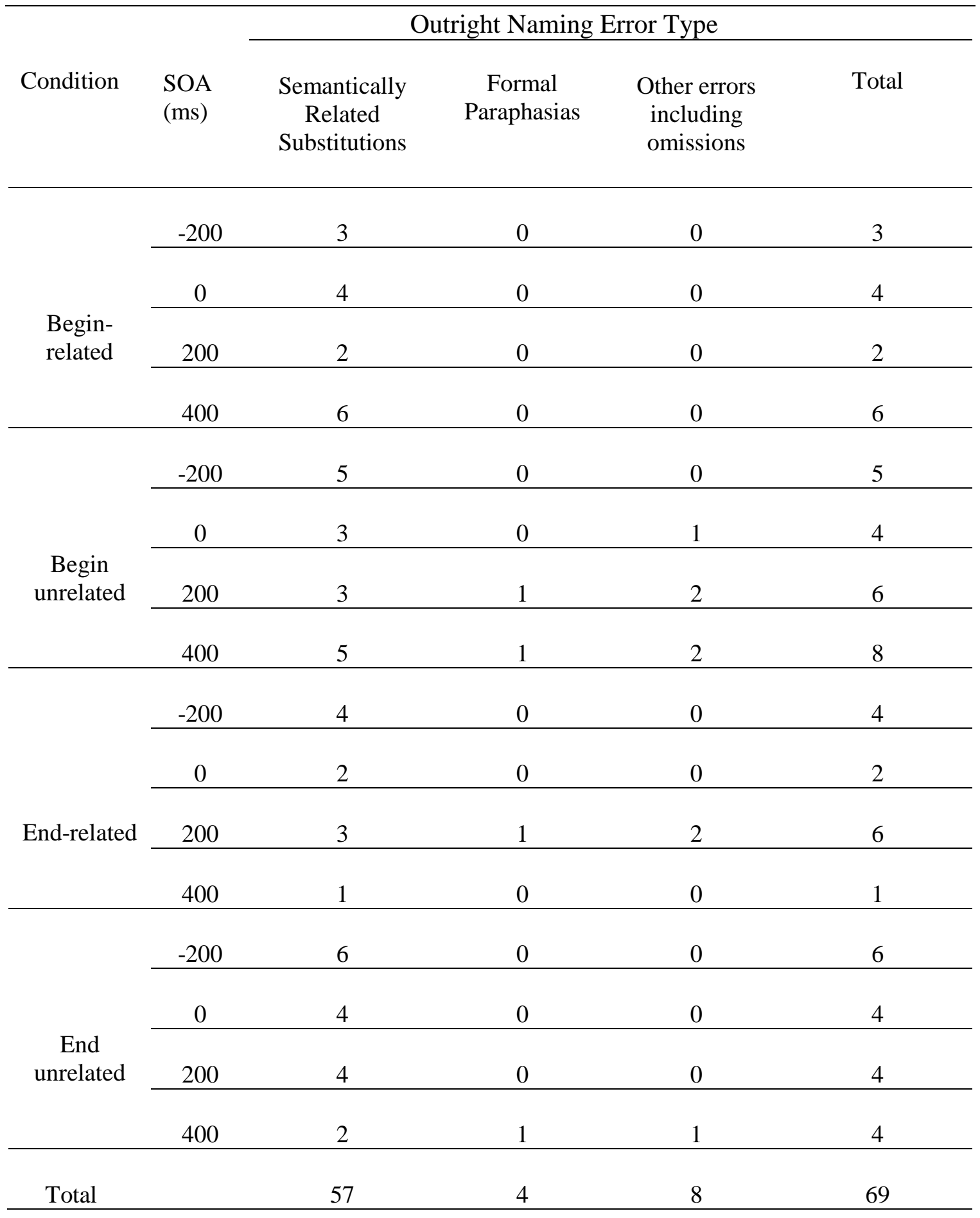


Word Form Retrieval in Spoken Word Production

A tally report of the types of outright naming errors and omissions made across the different distractor and SOA conditions for NP

\begin{tabular}{|c|c|c|c|c|c|}
\hline \multirow[b]{2}{*}{ Condition } & \multirow[b]{2}{*}{$\begin{array}{l}\text { SOA } \\
(\mathrm{ms})\end{array}$} & \multicolumn{3}{|c|}{ Outright Naming Error Type } & \multirow[b]{2}{*}{ Total } \\
\hline & & $\begin{array}{l}\text { Semantically } \\
\text { Related } \\
\text { Substitutions }\end{array}$ & $\begin{array}{c}\text { Formal } \\
\text { Paraphasias }\end{array}$ & $\begin{array}{l}\text { Other errors } \\
\text { including } \\
\text { omissions }\end{array}$ & \\
\hline \multirow{4}{*}{$\begin{array}{l}\text { Begin- } \\
\text { related }\end{array}$} & -200 & 4 & 0 & 4 & 8 \\
\hline & 0 & 4 & 1 & 3 & 8 \\
\hline & 200 & 3 & 1 & 2 & 6 \\
\hline & 400 & 1 & 0 & 6 & 7 \\
\hline \multirow{4}{*}{$\begin{array}{c}\text { Begin } \\
\text { unrelated }\end{array}$} & -200 & 3 & 1 & 6 & 10 \\
\hline & 0 & 5 & 0 & 11 & 16 \\
\hline & 200 & 6 & 0 & 8 & 14 \\
\hline & 400 & 7 & 1 & 10 & 18 \\
\hline \multirow{4}{*}{ End-related } & -200 & 6 & 0 & 6 & 12 \\
\hline & 0 & 6 & 3 & 6 & 15 \\
\hline & 200 & 4 & 0 & 8 & 12 \\
\hline & 400 & 5 & 0 & 8 & 13 \\
\hline \multirow{4}{*}{$\begin{array}{c}\text { End } \\
\text { unrelated }\end{array}$} & -200 & 3 & 0 & 10 & 13 \\
\hline & 0 & 3 & 0 & 9 & 12 \\
\hline & 200 & 4 & 1 & 6 & 11 \\
\hline & 400 & 5 & 0 & 8 & 13 \\
\hline Total & & 69 & 8 & 111 & 188 \\
\hline
\end{tabular}


1 Thanks to Carolyn Wilshire and Catherine Hodgson for making these materials available for this study

2 The CELEX frequencies contained some zero values, which cannot be directly entered into calculations that involve logarithmic transformations (e.g., t-tests of logged values or calculations of geometric means). Therefore, a value of 1 was added to each frequency value prior to calculation. The resultant values are referred to in the text as "corrected" frequency values. The geometric means presented are the values obtained using these "corrected" values, which were subsequently re-corrected by subtracting 1 . These values are referred to in the text as "estimated geometric means". These values provide a rough approximation of the "true" geometric mean.

3 Prior to obtaining the participant's grand mean, the latency data was windsorised (that is, the highest latency was replaced with the value for the next highest latency, and the second highest latency was replaced with the value of the third highest latency). This process reduces the influence of extreme outliers on calculation of the grand mean.

4 To obtain these values, we first calculated the standard deviation for the logtransformed data; then obtained the values that lay one standard deviation below and above the mean respectively. Then finally, we converted these values into the unlogged form for the purposes of presentation.

5 A pilot study carried out in the laboratory attempted to include a baseline measure using a tone condition together with the other distractor conditions. A 'startle effect' was discovered as participants became distracted or startled by the tone. This was characterised by extremely long naming latencies for trials that utlised the tone distractor. Future research could perhaps utilise a more balanced tone-distractor ratio (there were more trials that used the tone distractor compared to the other distractors); a different type of noise (e.g. white noise); or a standard no-distractor/silent condition. 